\title{
Kinetic Parameters for Biomass under Self-Ignition Conditions: Low-Temperature Oxidation and Pyrolysis
}

Schwarzer, Lars; Sárossy, Zsuzsa ; Jensen, Peter Arendt; Glarborg, Peter; Karlström, Oskar ; Holm, Jens Kai; Dam-Johansen, Kim

\section{Published in:}

Energy \& Fuels

Link to article, DOI:

10.1021/acs.energyfuels.9b00848

Publication date:

2019

Document Version

Peer reviewed version

Link back to DTU Orbit

Citation $(A P A)$ :

Schwarzer, L., Sárossy, Z., Jensen, P. A., Glarborg, P., Karlström, O., Holm, J. K., \& Dam-Johansen, K. (2019). Kinetic Parameters for Biomass under Self-Ignition Conditions: Low-Temperature Oxidation and Pyrolysis.

Energy \& Fuels, 33(9), 8606-8619. https://doi.org/10.1021/acs.energyfuels.9b00848

\section{General rights}

Copyright and moral rights for the publications made accessible in the public portal are retained by the authors and/or other copyright owners and it is a condition of accessing publications that users recognise and abide by the legal requirements associated with these rights.

- Users may download and print one copy of any publication from the public portal for the purpose of private study or research.

- You may not further distribute the material or use it for any profit-making activity or commercial gain

- You may freely distribute the URL identifying the publication in the public portal 


\title{
Kinetic parameters for biomass at self-ignition conditions: low-temperature oxidation and pyrolysis
}

\author{
Lars Schwarzer, ${ }^{* \dagger}$ Zsuzsa Sárossy, ${ }^{\dagger}$ Peter Arendt Jensen, ${ }^{*, \dagger}$ Peter Glarborg, ${ }^{\dagger}$ \\ Oskar Karlström, $\ddagger$ Jens Kai Holm, $₫$ and Kim Dam-Johansen ${ }^{\dagger}$ \\ $\dagger$ Department of Chemical and Biochemical Engineering, Technical University of Denmark, \\ Søltofts Plads 229, 2800 Kgs. Lyngby, Denmark \\ $\ddagger J o h a n$ Gadolin Process Chemistry Centre, Åbo Akademi University, Turku, Finland \\ ๆØrsted A/S, Nesa Allé 1, 2820 Gentofte, Denmark \\ E-mail: laschw@kt.dtu.dk; paj@kt.dtu.dk
}

\begin{abstract}
Pulverized biomass may self-heat and spontaneously ignite when stored or processed at intermediate or even low temperatures. In this work, reaction kinetic parameters for biomass oxidation and pyrolysis were determined for the temperature range $423-523 \mathrm{~K}$. Thermogravimetric analysis was used to determine mass loss kinetics in a stepwise-isothermal heating program. Two wood species (pine, beech), two agricultural residues (wheat straw, sunflower husks) and two commercial wood pellet samples were investigated. Atmospheres with $0 \%$, $20 \%$ and $80 \%$ oxygen were used in the experiments. A pyrolysis model of four parallel reactions for extractives, hemicellulose, celluose and lignin fit the experimental data for $0 \%$ $\mathrm{O}_{2}$ well. Oxidation kinetics could be modelled by additional reactions in parallel to the
\end{abstract}


pyrolysis mechanism. Two mechanisms were tested: (1) considering oxidation of a lumped 'volatilizable' component plus oxidation of char; and (2) separate oxidation reactions for volatilizable extractives, hemicellulose, celluose and lignin, plus char. The more complex mechanism did not give a clear advantage over the simpler mechanism. It was further found that pyrolysis and oxidation reactions for the components could be modelled with the same activation energy, regardless of which biomass they appear in. For the lumped component oxidation model, an apparent activation energy of $130 \mathrm{~kJ} / \mathrm{mol}$ was found. The observed reaction order in oxygen was in range $0.4-0.5$. The models also compared favorably to additional experimental data between $373-773 \mathrm{~K}$ for a heating rate of $5 \mathrm{~K} / \mathrm{min}$. The kinetic models presented here are intended mainly to describe low-temperature reactions, such as self-heating of biomass and the onset of smoldering combustion.

\section{Introduction}

Biomass can replace coal as a fuel for heat and power generation in pulverized fuel fired boilers. One recent example is the conversion of Danish combined heat and power (CHP) plants originally built as pulverized-coal fired boilers. This technological switch requires to store and process solid biomass materials, mainly in form of pellets, in large quantities. In CHP-facilities, fires have occured in storages and power plant mills that were likely caused by spontaneous ignition. Excessive self-heating, leading to thermal decomposition and ignition, is a known problem for storages. ${ }^{1,2}$ To the authors' knowledge, the role of self-ignition of biomass in mill fires, i.e. at elevated temperatures above $423 \mathrm{~K}$, has not been explicitly researched. However, based on older studies of coal mills, settled dust beds may build up and self-ignite in these devices. ${ }^{3-5}$ Predicting such events requires accurate reaction kinetic data for low temperatures. Unfortunately, such data are scarce for typical fuels such as wood pellets and agricultural residues.

Additionally, there does not appear to be a consensus on the appropriate kinetic model 
for low temperature oxidative conversion. Different researchers have proposed single-reaction models, ${ }^{1,6-10}$ models with two or more parallel reactions, ${ }^{11-17}$ models with two or more sequential reactions, ${ }^{18-20}$ and models involving combinations of serial and parallel reactions. ${ }^{21-26}$ Where several reactions are used, these have been used to distinguish between pyrolysis and oxidation, between different biomass components, or different stages of pyrolysis and/or oxidation reaction pathways. A short overview will be given below in the light of determining kinetic parameters at temperatures relevant to self-heating in power plant mills.

If only a single reaction is used to model low temperature oxidation, the reported kinetic parameters vary widely. Activation energies for wood pellets from isothermal calorimetry at low temperatures $(300-350 \mathrm{~K})$ have been measured as $50-80 \mathrm{~kJ} / \mathrm{mol}{ }^{1,7}$ From oven heating tests, $89 \mathrm{~kJ} / \mathrm{mol}$ are reported for mahogany wood at $375-450 \mathrm{~K} .{ }^{11}$ Data compiled from oven tests of different wood species at $370-570 \mathrm{~K}$ result in activation energies of $110-125 \mathrm{~kJ} / \mathrm{mol} .{ }^{6}$

From self-ignition oven tests according to EN 15188, activation energies of $139 \mathrm{~kJ} / \mathrm{mol}$ and $207 \mathrm{~kJ} / \mathrm{mol}$ are reported for sunflower husk pellets and softwood chips, respectively. ${ }^{10}$ Kinetic parameters from tests on larger samples may also be influenced by heat and mass transfer limitations. Thermogravimetric analysis (TGA) is considered a method to avoid such transport limitations. Single-reaction models have been fit to TGA data, and activation energies for oxidation of forestry and agricultural residues are given in the range of 61$68 \mathrm{~kJ} / \mathrm{mol}(\text { at } 293-1073 \mathrm{~K})^{9}$ and $75-116 \mathrm{~kJ} / \mathrm{mol}($ at $500-630 \mathrm{~K}){ }^{8}$

Thermogravimetric analysis has also been used to determine reaction kinetic parameters for biomass oxidation and pyrolysis in more complex models. ${ }^{12-20,22-26}$ The most widespread method is to conduct experiments at several constant heating rates from ambient conditions to temperatures exceeding $873 \mathrm{~K}$ or higher. The experimental data are in turn used to fit the parameters of a reaction model consisting of two or more seuqential or parallel reactions, so that this best matches the conversion rate $d X / d t$ as a function of temperature. Mass loss at low temperatures $(<470-525 \mathrm{~K})$ is frequently very low, however, and not well resolved 
in the reported experimental data. In the few cases in which mass loss is reported at these temperatures, it is attributed to evaporation of moisture. ${ }^{25,26}$ In both of those cited works, the evaporation peak is also clearly offset from oxidation and/or pyrolysis of the organic fraction when plotting conversion rate over temperature. Significant thermal or oxidative degradation below $470 \mathrm{~K}$ is not described in any of the cited TGA-studies. ${ }^{12-20,22-26}$ Comparison with the experiments at low temperatures $(370-570 \mathrm{~K})$ and long holding times (minutes to years), 1,6,7,11 where significant conversion of the organic fraction is observed, suggests that the heating rates used in typical TGA-studies are too high to resolve the slow reactions at low temperatures. While experimental procedures slightly vary among researchers, ${ }^{12-20,22-26}$ the lower bound for heating rates is usually $5-10 \mathrm{~K} / \mathrm{min}$ (Anca-Couce et al. ${ }^{14}$ also investigated $2.5 \mathrm{~K} / \mathrm{min}$ ), with an upper bound of typically $20-40 \mathrm{~K} / \mathrm{min}$. Such heating rates are interesting to describe propagation of smoldering combustion, which is associated with heating rates in order of $10-1000 \mathrm{~K} / \mathrm{min} .{ }^{21}$ In contrast, this work focuses on the initiation and onset of smoldering. Based on practical experience with ignition in mill fires, it is suspected that this incipient smoldering occurs on much larger timescales and at lower temperatures. Isothermal ${ }^{27-30}$ and stepwise isothermal thermogravimetric analysis ${ }^{31,32}$ have been used to investigate torrefaction reactions (a mild pyrolysis, $\approx 473-573 \mathrm{~K}$ ), while only few comparable works are available for oxidative atmosphere (e.g., $\left.{ }^{33}\right)$.

The aim of this work is to extend kinetic models of devolatilization and oxidation to lower temperatures and heating rates. We present a model to describe mass loss kinetics for six different biomasses, distinguishing between pyrolysis and heterogeneous oxidation as parallel processes. Thermogravimetric analysis with stepwise isothermal programs in the range of $423-523 \mathrm{~K}$ is used to find the values of the kinetic parameters for each of the biomasses investigated. The oxygen concentration is varied in the experiments $(0 \%, 20 \%$ and $80 \%$ oxygen) to separate purely thermal decomposition (pyrolysis) from oxidative reactions, and to determine the influence of oxygen on the reaction rates. The kinetic models found for low temperatures under isothermal conditions are then compared to thermogravimetric 
experiments at intermediate heating rates $(5 \mathrm{~K} / \mathrm{min})$ and temperature ranges $373-773 \mathrm{~K}$ to ensure that they are consistent with the data available in the literature for those conditions.

\section{Experimental}

Six different biomasses were investigated: beech wood, pine wood and wheat straw as raw materials, as well as two types of wood pellets obtained from a local CHP-plant, and a sample of sunflower husk pellets as commercial pelletized fuels. Additionally, experiments were carried out with cellulose (Sigma-Aldrich C6288), xylan (from cornstalk; abcr Chemie AB143294) and lignin (alkali; Sigma-Aldrich 471003). Rapeseed oil was used as a model substance for extractives, as it contains a mix of saturated and unsaturated fatty acids (mainly C18:1 and C18:2). Unsaturated fatty acids may play a role in the autooxidation of biomass. $^{2}$ In order to model extractives bound in a matrix, experiments were carried out with mixtures of oil and $\mathrm{SiO}_{2}$ as well as oil and cellulose, both $50 \% / 50 \%$ by weight.

The two woods were provided in pulverized form (beech: 0-250 $\mu \mathrm{m}$, pine: 50-200 $\mu \mathrm{m}$ ). The other biomass samples were milled and a size fraction $<125 \mu \mathrm{m}$ was used in the experiments. Cellulose, lignin and xylan were used as provided by the manufacturer. Information on the chemical properties of the six biomass materials used is found in Table 1. Results from proximate and ultimate analysis fall within the range of values typically found in the literature, although pine and wood pellets appear to have low char and high volatile contents. Of the inorganic elements present in the samples, especially potassium and sodium

are known to have a catalytic effect on thermal conversion. ${ }^{30,34-37}$ Other metals observed to have catalytic effects are magnesium ${ }^{30}$ and, to a lesser extent, calcium. ${ }^{34}$

\subsection{Biopolymer analysis}

Klason lignin and carbohydrate composition of the six samples were determined by sulfuric acid hydrolysis. $1.5 \mathrm{~mL}$ of $72 \% \mathrm{H}_{2} \mathrm{SO}_{4}$ were added to $0.16 \mathrm{~g}$ sample, which was pre- 
hydrolyzed for 60 minutes at $303 \mathrm{~K}$. After dilution of the hydrolyzate with Milli-Q purified water $(42 \mathrm{~mL})$, the liquid samples were autoclaved at $393 \mathrm{~K}$ for further 60 minutes. Filtered liquids were analyzed on an HPLC (high-pressure/high-performance liquid chromatography) column, while the solid residue was heated to $823 \mathrm{~K}$ to determine the lignin ash content. Results are summarized in Table 1. For the two wood pellet samples, analyses from an external lab were available. The results agreed with the ones presented here within $\pm 0.01 \mathrm{~kg} / \mathrm{kg}$, with the exception of glucose $(0.401 \mathrm{~kg} / \mathrm{kg}$ and $0.395 \mathrm{~kg} / \mathrm{kg}$ for wood pellets I1 and I2, repsectively), which showed slightly larger deviations.

Acid methanolysis and GC-MS (gas chromatography - mass spectrometry) was applied to three of the biomass samples in order to separate and quantify their hemicellulose-bound glucose content. The method is described elsewhere in more detail. ${ }^{38}$ The analysis was done in duplicate and results were repeatable within $10 \%$ of the reported values. Data is included in Table 1, based on the total dry matter.

Extractives were measured following a procedure based on an NREL report, Determination of Extractives in Biomass (NREL/TP-510-42619). Lipids were extracted with ethanol $(96 \mathrm{v} / \mathrm{v} \%)$ in a Soxhlet extractor for 6 hours to measure the amount of total extractives. The extracts were then chemically modified with $1.25 \mathrm{M} \mathrm{HCl}$ in methanol to produce fatty acid methyl esters, so that the fatty acids become detectable for the GC-MS instrument. An Agilent 7890B gas chromatograph interfaced to an Agilent 5977B Mass Selective Detector was used in this part of the study. Samples of $1 \mu \mathrm{L}$ were injected in split mode (1:20). The source and rod temperatures were $503 \mathrm{~K}$ and $423 \mathrm{~K}$, respectively. The products were separated using two HP-5ms ultra inert columns $(15 \mathrm{~m}, 0.25 \mathrm{~mm}, 0.25 \mu \mathrm{m}$ coating). Separation of products was achieved using a temperature program from $343-523 \mathrm{~K}$ at $10 \mathrm{~K} / \mathrm{min}$. Results are included in Table 1, where the relative abundance of the $\mathrm{C} 16: 0-\mathrm{C} 22: 0$ fatty acids are given for each biomass. The fatty acid values given are proportions, and do not allow an absolute quantification. 
Table 1: Proximate, elemental and compositional analysis of the biomasses used used in this study. Difference to one in the sum of the compositional analysis is balance error.

\begin{tabular}{|c|c|c|c|c|c|c|}
\hline & Beech & Pine & Sunflower & Wheat & W. pellets I1 & W. pellets I2 \\
\hline \multicolumn{7}{|c|}{ Proximate analysis, dry base $[\mathrm{kg} / \mathrm{kg}]$} \\
\hline Volatiles & 0.771 & 0.856 & 0.756 & 0.774 & 0.845 & 0.839 \\
\hline Char & 0.202 & 0.141 & 0.193 & 0.184 & 0.149 & 0.155 \\
\hline Ash & 0.027 & 0.003 & 0.052 & 0.042 & 0.006 & 0.006 \\
\hline Moisture (average) & 0.059 & 0.049 & 0.085 & 0.061 & 0.060 & 0.057 \\
\hline \multicolumn{7}{|c|}{ Elemental analysis, dry base $[\mathrm{kg} / \mathrm{kg}]$} \\
\hline $\mathrm{C}$ & 0.512 & 0.528 & 0.521 & 0.480 & 0.507 & 0.511 \\
\hline $\mathrm{H}$ & 0.057 & 0.061 & 0.059 & 0.057 & 0.061 & 0.061 \\
\hline $\mathrm{O}$ & 0.429 & 0.410 & 0.503 & 0.457 & 0.430 & 0.427 \\
\hline $\mathrm{N}$ & 0.002 & 0.001 & 0.015 & 0.004 & 0.002 & 0.001 \\
\hline \multicolumn{7}{|c|}{ Inorganic elements (selection), dry base $[\mathrm{mg} / \mathrm{kg}]$} \\
\hline $\mathrm{Ca}$ & 4600 & 900 & 2600 & 2300 & 2000 & 1400 \\
\hline K & 4600 & 360 & 8000 & 7500 & 1200 & 640 \\
\hline $\mathrm{Mg}$ & 830 & 130 & 1400 & 690 & 420 & 320 \\
\hline $\mathrm{Na}$ & 280 & 71 & 10 & 260 & 33 & 94 \\
\hline \multicolumn{7}{|c|}{ Compositional analysis, dry base $[\mathrm{kg} / \mathrm{kg}]$} \\
\hline Arabinose & 0.005 & 0.015 & 0.022 & 0.032 & 0.010 & 0.014 \\
\hline Galactose & 0.007 & 0.025 & 0.009 & 0.011 & 0.013 & 0.026 \\
\hline Mannose & 0.015 & 0.117 & 0.006 & 0.005 & 0.046 & 0.106 \\
\hline Rhamnose & 0.004 & 0.002 & 0.008 & 0.002 & 0.003 & 0.002 \\
\hline Xylose & 0.168 & 0.055 & 0.174 & 0.271 & 0.134 & 0.074 \\
\hline Galacturonic acid & 0.025 & 0.013 & 0.048 & 0.008 & 0.024 & 0.013 \\
\hline Glucuronic acid & 0.001 & 0.001 & 0.006 & 0.004 & 0.001 & - \\
\hline Sum non-glucose sugars & 0.225 & 0.228 & 0.273 & 0.333 & 0.231 & 0.235 \\
\hline Glucose (total) & 0.337 & 0.440 & 0.270 & 0.424 & 0.423 & 0.431 \\
\hline Non-cellulose glucose & 0.016 & 0.037 & 0.009 & n.a. & n.a. & n.a \\
\hline Klason lignin & 0.346 & 0.278 & 0.316 & 0.208 & 0.273 & 0.316 \\
\hline Extractives & 0.015 & 0.093 & 0.089 & 0.039 & 0.066 & 0.072 \\
\hline Sum (composition) & 0.923 & 1.039 & 0.948 & 1.004 & 0.993 & 1.054 \\
\hline Lignin ash & 0.009 & 0.002 & 0.006 & 0.014 & 0.006 & 0.004 \\
\hline \multicolumn{7}{|c|}{ Fatty acids analysis, relative abundance [arbitrary units] } \\
\hline C 16:0 & 0.255 & 0.045 & 0.101 & 0.332 & 0.200 & 0.158 \\
\hline C 18:0 & 0.058 & n.a & 0.084 & 0.052 & 0.038 & 0.046 \\
\hline C 18:1 & 0.190 & 0.207 & 0.199 & 0.123 & 0.188 & 0.184 \\
\hline C $18: 2$ & 0.082 & 0.020 & 0.231 & 0.045 & 0.186 & 0.025 \\
\hline C $18: 3$ & n.a. & n.a. & 0.046 & n.a. & 0.038 & n.a. \\
\hline C 20:0 & 0.039 & n.a. & 0.018 & 0.020 & 0.024 & n.a. \\
\hline C 22:0 & 0.108 & 0.024 & n.a. & 0.036 & 0.034 & n.a. \\
\hline
\end{tabular}




\subsection{Thermogravimetric analysis}

Thermogravimetric measurements were carried out on a Netzsch STA 449-F1 Jupiter. The instrument was checked by repeating a round-robin study on cellulose pyrolysis, ${ }^{39}$ as well as repeating pyrolysis experiments on beech ${ }^{40}$ and pine $e^{14,40}$ at a heating rate of $5 \mathrm{~K} / \mathrm{min}$. Agreement between our data and the kinetic models presented in the literature ${ }^{14,39,40}$ was good. It was also found that kinetics derived from TGA with $5 \mathrm{~K} /$ min heating rates does not predict low-temperature mass loss well (see supporting information).

The focus of this work is on low temperature kinetics. Therefore, a temperature program for the TGA experiments was designed to investigate the region $423-523 \mathrm{~K}$. The program consisted of a series of six isothermal stages: $423 \mathrm{~K}, 443 \mathrm{~K}, 463 \mathrm{~K}, 483 \mathrm{~K}, 503 \mathrm{~K}$ and $523 \mathrm{~K}$. Each isothermal condition was held for one hour, with heating rates of $10 \mathrm{~K} / \mathrm{min}$ in between stages and up to the first isothermal holding point (compare the top part of Fig. 1). Temperatures measured at the sample crucible generally followed the preset temperature programs well. A mild excess in temperature was seen at the beginning of each isothermal interval, which was attributed to a controller overshoot. The measured temperature history was used in the analysis of the data.

The gas flow rate through the oven was $150 \mathrm{~mL} / \mathrm{min}$, and experiments were run under $0 \%, 20 \%$ and $80 \%$ oxygen (balance: nitrogen). Experiments were duplicated in range $423-$ $503 \mathrm{~K}$. To compare kinetic parameters determined in this work to data available in the literature, additional experiments were carried out at a constant heating rate of $5 \mathrm{~K} / \mathrm{min}$ from ambient to $773 \mathrm{~K}$, both under inert atmosphere and with $10 \%$ and $20 \%$ oxygen each. These experiments were also duplicated.

Samples were placed in alumina cups of $7 \mathrm{~mm}$ diameter and $4 \mathrm{~mm}$ height, which were filled to less than a third of their height. For the $5 \mathrm{~K} /$ min temperature-ramp experiments, the sample mass was kept below $5 \mathrm{mg}$ to avoid mass- and heat transfer limitations. For the

isothermal experiments, slightly higher sample masses of $<10 \mathrm{mg}$ were allowed in order to better resolve the low mass loss at low temperatures. 
The biomass samples were used as-is, i.e. without prior drying. Evaporation of moisture was clearly visible in the recorded data as a pronounced loss of mass (between 4-8\% depending on the individual sample, with typical values around $5 \%$ of the total) within the first 10 minutes of the experiment. As evaporation of moisture and decomposition of the organic matter were easily distinguished, no dedicated drying period was included in the heating programs. The measured moisture content was used to rescale the data to dry values.

Data were automatically recorded in 0.05-minute intervals for isothermal experiments, and in 0.01-minute intervals at constant heating rate. The sampling rates follow the default settings of the instrument. Recorded mass loss data were corrected for buyoancy effects by subtracting a correction carried out on an empty crucible for each experimental program. A simple routine for pre-processing the data was developed and applied to all datasets. Mass loss data were rescaled to dry-base for further treatment, and $m_{0}$ refers to the initial dry mass in the following. To determine the conversion $X$,

$$
X(t)=\frac{m_{0}-m(t)}{m_{0}-m_{\mathrm{f}}}
$$

the final mass $m_{f}$ was set to the sum of char and ash (from proximate analysis) for pyrolysis experiments, and only ash for experiments under oxidative atmosphere. Ash and char contents are found in Table 1. Owing to noise on the measured signal, the conversion rates $d X / d t$ were determined from smoothed data. Data were initially smoothed by calculating the moving average of $X(t)$ with a filter width of 120 records. From these data, the conversion rate was calculated as the temporal gradient by central differences. The conversion rate was then filtered again by applying the same moving average filter.

Repeatability of the experiments was generally good. In order to compare duplicate runs, the root-mean-square (RMS) difference was used.

$$
\delta_{\varphi}=\sqrt{\frac{\sum\left(\varphi_{1}(t)-\varphi_{2}(t)\right)^{2}}{N}} ; \quad \varphi=\left\{m / m_{0}, d X / d t, T\right\}
$$


In this equation, $N$ is the total number of datapoints measured at time $t$, and $\varphi$ is a placeholder for the compared quantities: remaining mass scaled by initial mass, conversion rate and temperature. This difference can also be scaled to the range of $\varphi$-values by

$$
\delta_{\mathrm{S}, \varphi}=\frac{\delta_{\varphi}}{\varphi_{\max }-\varphi_{\min }}
$$

Root-mean-square differences, data range, and scaled differences were determined individually for each biomass sample in each temperature program. In the following, only the maximum differences and scaled differences across all measurements are given. The temperaturetime programs agreed within a difference of $\delta_{T}=0.35 \mathrm{~K}$ for all experiments. The relative mass remaining $\mathrm{m} / \mathrm{m}_{0}$ was repeatable within 0.0094 (6.5\% of the measured range) for the isothermal experiments and 0.015 (1.8\% of the measured range) for the constant heating rate experiments. For the conversion rates, the corresponding maximum RMS-differences were $7.5 \times 10^{-6} \mathrm{~s}^{-1}($ scaled $13.3 \%)$ for the isothermal experiments and $3.0 \times 10^{-5} \mathrm{~s}^{-1}$ (scaled $3.4 \%$ ) for experiments at constant heating rate of $5 \mathrm{~K} / \mathrm{min}$. Scaled RMS-differences of $m / m_{0}$ and $d X / d t$ in the isothermal experiments are generally higher owing to the low overall conversion or mass loss at the low temperatures $(<503 \mathrm{~K})$ for which those experiments were repeated.

Experimental data from thermogravimetric analysis are summarized in Figures 1 and 2. The data from isothermal experiments clearly reveals differences among the different biomasses in the temperature range $423-523 \mathrm{~K}$. Sunflower husk pellets show the highest mass loss through most of the temperature range tested. The two wood pellets are among the least reactive in the entire temperature range of the isothermal experiments. Pine initially loses mass at rates similar to sunflower, but is less reactive at higher temperatures $(\geq 483 \mathrm{~K})$. The opposite is observed for wheat and beech, for which mass loss accelerates above this temperature. Measured mass loss in oxidative atmosphere differs from that in inert atmosphere from approximately the third isothermal stage $(463 \mathrm{~K})$ onward. It was considered 


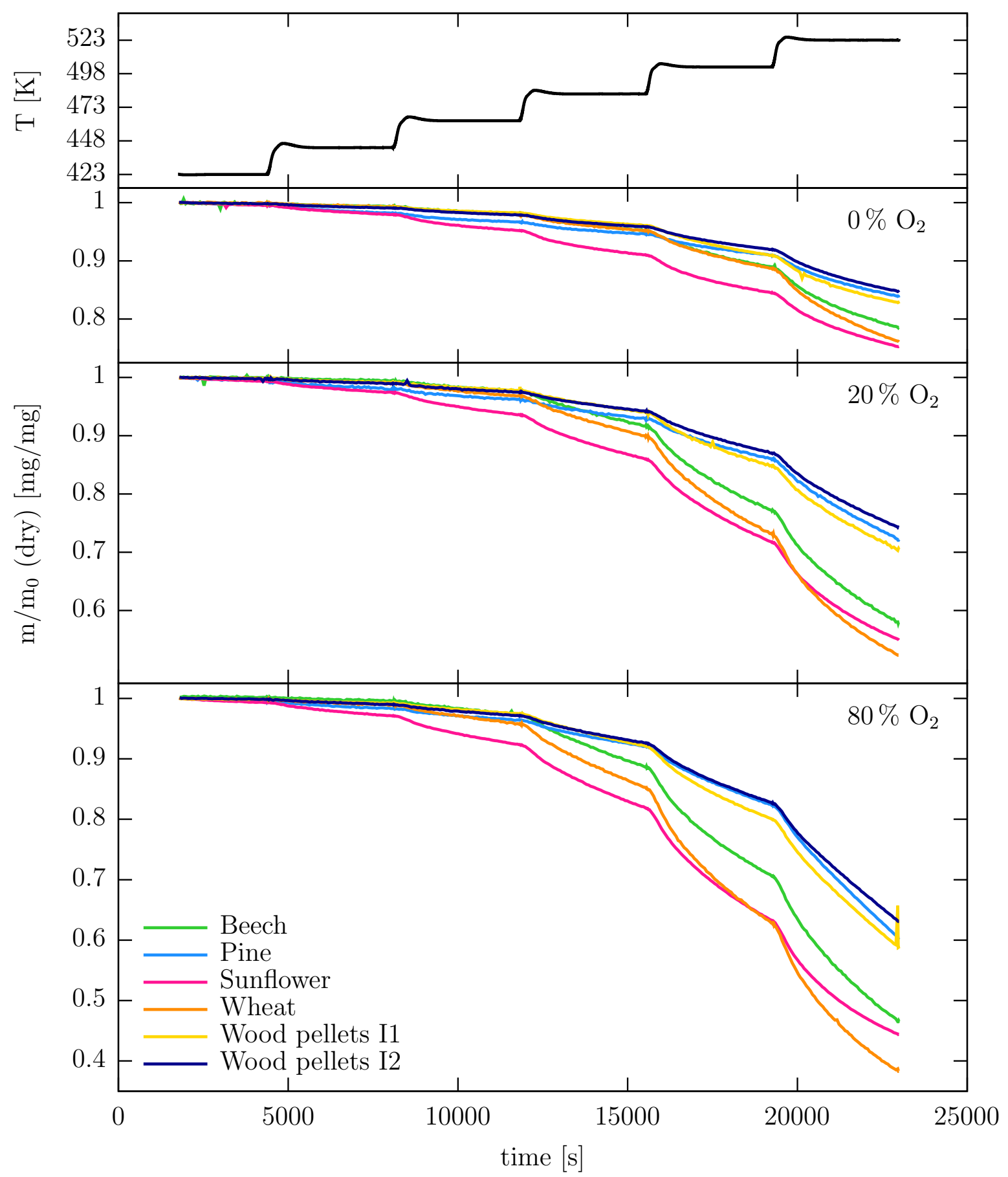

Figure 1: Experimental data from isothermal experiments reveals differences both between biomasses and between heating in oxidative and inert atmosphere in range 423-523 K. From top to bottom: measured (actual) heating profile, measured mass loss (scaled) in $0 \%$ oxygen, $20 \%$ oxygen and $80 \%$ oxygen atmosphere 


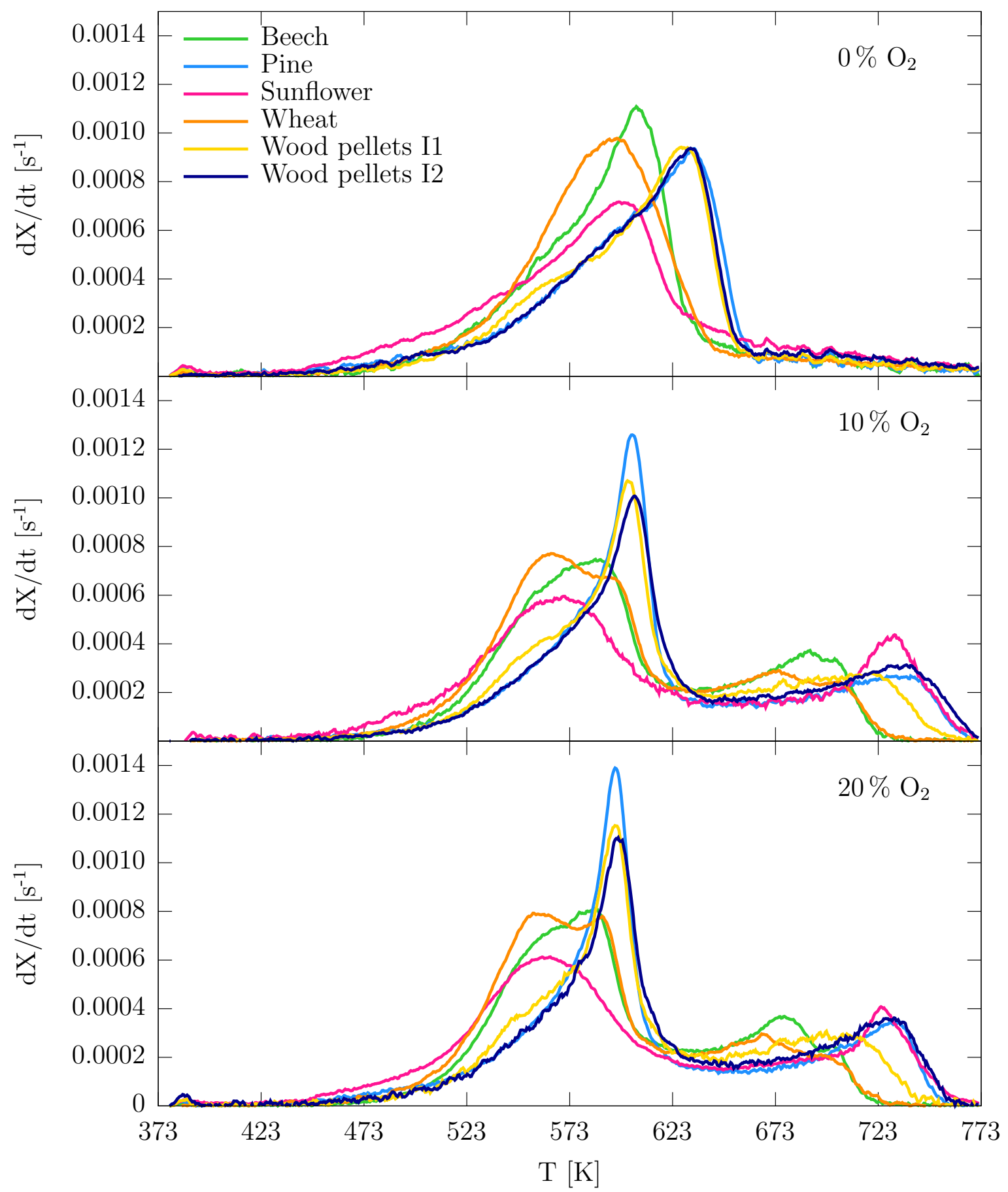

Figure 2: Experimental data from $5 \mathrm{~K} /$ min experiments does not allow to distinguish between fuel (except sunflower) in range $423-523 \mathrm{~K}$. Differences in conversion rate as a function of temperature are most apparent between $523-623 \mathrm{~K}$. From top to bottom: in $0 \%$ oxygen, $10 \%$ oxygen and $20 \%$ oxygen atmosphere 
whether air entrapped in the sample beds may lead to few, early oxidation reactions, even when the experiments are run with nitrogen atmosphere. However, interstitial air could only supply $<0.2 \%$ of the oxygen necessary for conversion of the sample, and the entrapped oxygen is additionally expected to diffuse out rapidly. Purge flow rates of $150 \mathrm{~mL} / \mathrm{min}$ are moreover sufficient to replace the gas volume enclosed in the oven in the first few minutes of the experiment.

For the experiments at constant heating rate, the conversion rate is shown as a function of temperature to allow better comparison with the data available in literature. ${ }^{8,12-17,22,24-26,44}$ With the exception of sunflower, these data does not allow to distinguish between different biomasses and different atmospheres below $473 \mathrm{~K}$. The dominating feature in this data presentation is the peak in conversion rate, typically attributed to reactions of cellulose. Presence of oxygen is seen to accelerate mass loss in all cases, in agreement with published data. However, the effect of oxygen concentration is small, when comparing the experiments under $10 \%$ and $20 \%$ oxygen atmosphere. The location of the peak decomposition rate is shifted by $5-10 \mathrm{~K}$, and the rates themselves are slightly higher. With oxygen present, two characteristic peaks can be seen. The secondary peaks in range $\geq 673 \mathrm{~K}$ can likely be attributed to char oxidation.

Dimensionless Biot (Bi), Pyrolysis (Py) and Damköhler (Da) numbers were evaluated to determine the influence of heat transfer limitations (during transient heating) and mass transfer limitations (for oxidation experiments). Heat transfer has negligble influence on the observed mass loss, when internal heat transfer is faster than external heat transfer $(\mathrm{Bi} \ll 1)$, and when both are faster than reaction rates $(\mathrm{Py} \gg 1) .{ }^{41,42}$ Mass transfer limitations are considered for oxygen only, and kinetic control can be assumed when diffusion rates are faster than reaction rates $(\mathrm{Da} \ll 1)$. Addiditonally, the dimensionless Frank-Kamenetskiiparameter $^{43}$ was calculated to determine whether thermal runaway (heat release exceeds internal heat dissipation) could occur in the samples with oxygen present. Details of these calculations can be found in the supporting information. Based on the evaluation of the 
dimensionless parameters, conditions for the stepwise isothermal experiments were free from heat- and mass transfer limitations. Transport limitations may play a minor role for the experiments at constant heating rate: The Biot number becomes independent of particle or sample size for near-stagnant flows. ${ }^{42} \mathrm{Bi}$ evaluated to $0.1-0.2$ for single particles and $\mathrm{Bi}<0.4$ for the full sample (i.e., the bed of particles). The Pyrolysis number criterion can be used to estimate a critical maximum particle size. ${ }^{42}$ Using this approach, kinetic control is predicted up to $700 \mathrm{~K}$ (pyrolysis) and $625 \mathrm{~K}$ (oxidation) based on modelled rates for the largest particles used $(250 \mu \mathrm{m})$. Oxygen diffusion limitations were estimated to be wholly negligible below $570 \mathrm{~K}$. By conservative estimate, self-ignition of the samples cannot occur below $530 \mathrm{~K}$ under the experimental conditions used, and no self-heating was observed in the experiments. Other possible influences, such as particle specific surface area, particle porosity and bed structure were not quantified. The former two would influence availability

of active sites to oxygen attack, while the latter determine diffusion through the sample as well as the bed thermal conductivity. While kinetic control was assumed in interpreting the experiments, the results are strictly valid only for the size range and morphology of the particles used.

\section{$3 \quad$ Modelling}

Reactions are described by a differential equation for the conversion $X$,

$$
\frac{d X}{d t}=k(T) \cdot f_{1}(X) \cdot f_{2}\left(p_{\mathrm{O}_{2}}\right)
$$

$k$ is the rate constant modelled by an Arrhenius-expression,

$$
k=k_{0} \cdot \exp \left(-\frac{E_{\mathrm{a}}}{R \cdot T}\right)
$$


and $f_{1}$ and $f_{2}$ are functions of conversion and oxygen partial pressure, respectively. Most common models for $f_{1}$ are first- or $n$-order reactions:

$$
f_{1}(X)=(1-X)^{n_{1}}
$$

Oxygen-dependent reactions can be modelled by introducing a reaction order in oxygen partial pressure,

$$
f_{2}\left(p_{\mathrm{O}_{2}}\right)=\left(\frac{p_{\mathrm{O}_{2}}}{p_{\text {ref }}}\right)^{n_{2}}
$$

where a reference pressure $p_{\text {ref }}$ is introduced to non-dimensionalize the oxygen partial pressure.

Initial attempts at fitting a single first order reaction to the pyrolysis experiment and combining it with a first order reaction for oxidation yielded poor fits. The quality of the model fit could be improved slightly when an n-order reaction was considered. However, fitting only selected temperature ranges of the experimental mass loss curve yielded different sets of kinetic parameters, indicating that a process consisting of several steps was taking place.

Several researchers have linked these steps in the reaction to parallel and independent reactions of the components hemicellulose, cellulose and lignin. ${ }^{13-18,25,45}$ In this work, extractives are considered as a separate fourth component. Pyrolysis and oxidation of these four components are modelled as parallel reactions, similar to literature. ${ }^{12,14,23,25,26}$ For consistency, char is included as an additional fifth component. Char is defined as the remainder of a complete biomass devolatilization in this model. Char oxidation dominates at higher temperatures, when the volatilizable fractions of hemicellulose, cellulose, lignin and extractives have been removed. Although this process is physically in sequence to pyrolysis and primary oxidation, several authors have demonstrated that, mathematically, it may also be modelled as an additional parallel reaction. ${ }^{13-17}$ Following this approach, it is not necessary to track 
the formation of char. Instead, the biomass components are split into volatilizable and nonvolatilizable fractions, i.e. char is considered present already in the unreacted biomass from a modelling point of view. Considering the non-volatilizable fractions as a lumped species, the following mechanism of nine parallel reactions is applied:

$$
\begin{array}{ll}
\text { XTR } & \rightarrow \text { Volatiles } \\
\mathrm{HC} & \rightarrow \text { Volatiles } \\
\mathrm{LIG} & \rightarrow \text { Volatiles } \\
\mathrm{CELL} & \rightarrow \text { Volatiles } \\
\mathrm{XTR}+\mathrm{O}_{2} \rightarrow \text { Gas } & \\
\mathrm{HC}+\mathrm{O}_{2} \rightarrow \text { Gas } \\
\mathrm{LIG}+\mathrm{O}_{2} \rightarrow \text { Gas } \\
\mathrm{CELL}+\mathrm{O}_{2} \rightarrow \text { Gas } \\
\text { CHAR }+\mathrm{O}_{2} \rightarrow \text { Gas }
\end{array}
$$

Reactions R1-4 represent pyrolysis of the volatilizable fractions of extractives (XTR), hemicellulose (HC), lignin (LIG) and cellulose (CELL) components. Reactions R5-8 are the corresponding oxidation reactions. The final reaction R9 describes the oxidation of char, regardless of the component or reaction pathway it originates from. The conversion $X_{\mathrm{i}}$ of each of the five species (volatilizable extractives, hemicellulose, lignin and cellulose, plus char) is then described by:

$$
\frac{d X_{\mathrm{i}}}{d t}=k_{\mathrm{pyr}, \mathrm{i}} \cdot\left(1-X_{\mathrm{i}}(t)\right)^{n_{\mathrm{pyr}, \mathrm{i}}}+k_{\mathrm{ox}, \mathrm{i}} \cdot\left(1-X_{\mathrm{i}}(t)\right)^{n_{\mathrm{ox}, \mathrm{i}}} \cdot\left(\frac{p_{\mathrm{O}_{2}}}{p_{\mathrm{ref}}}\right)^{n_{\mathrm{O}_{2}, \mathrm{i}}}
$$

where $n$ is the apparent reaction order and the rate constant $k$ is expressed by an Arrhenius 
law.

$n_{\mathrm{O}_{2}}$ is the reaction order with respect to partial pressure of oxygen $p_{\mathrm{O}_{2}}$. The reference pressure $p_{\text {ref }}$ is used to non-dimensionallize this quantity. Here, $p_{\text {ref }}$ is simply 1 Pa. For char, i.e. the non-volatilizable organic fraction, $k_{\mathrm{pyr}}=0$. Since only the reacting fractions of the components are considered (i.e. $m_{i, f}=0$ ), the remaining mass fraction of each component $i$ is given by

$$
w_{\mathrm{i}}(t)=\frac{m_{\mathrm{i}}(t)}{m_{\mathrm{i}, 0}}=1-X_{\mathrm{i}}(t)
$$

If $w_{i, 0}$ is the original mass fraction of species $i$, then the total mass fraction is given by:

$$
w(t)=\frac{m(t)}{m_{0}}=\sum_{i} w_{\mathrm{i}, 0} \cdot w_{\mathrm{i}}(t)
$$

The amount of ash is constant. The model requires five parameters for the original mass fractions $w_{\mathrm{i}, 0}$, as well as four reaction kinetic triplets $\left\{E_{\mathrm{a}}, k_{0}, n_{\mathrm{pyr}}\right\}$ for the pyrolysis reactions and five sets $\left\{E_{\mathrm{a}}, k_{0}, n_{\mathrm{ox}}, n_{\mathrm{O}_{2}}\right\}$ for the oxidation reactions, i.e. a total of 37 parameters per fuel.

In order to reduce the model complexity, the following assumptions are made:

1. The fractions of extractives, hemicellulose, cellulose and lignin can be estimated from the composition analysis (Table 1).

2. The total char yield can be determined from the ultimate analysis. The individual char yield of the components extractives, hemicellulose, cellulose and lignin, i.e. the split into volatilizable and non-volatilizable fractions, can be estimated from the behavior of the pure components.

3. Similar sets of activation energies $E_{\mathrm{a}, \mathrm{pyr}, \mathrm{i}}$ and $E_{\mathrm{a}, \mathrm{ox}, \mathrm{i}}$ can be found for each component $i$, regardless of which biomass they appear in. The activation energies can be estimated from the behavior of the pure components. 
4. Similar sets of apparent reaction orders in the solid conversion $\left(n_{\mathrm{pyr}, \mathrm{i}}\right.$ and $\left.n_{\mathrm{ox}, \mathrm{i}}\right)$ can be found for each component $i$, regardless of which biomass they appear in.

By combining the first two assumptions, the original mass fractions $w_{\mathrm{i}, 0}$ can be found. The third assumption fixes all activation energies, so they need not be included in the parameter fitting routine. The different biomass conversion models are then defined by 23 parameters: 8 belonging to the four pyrolysis reactions, i.e. $\left\{k_{0, \text { pyr }}, n_{\text {pyr }}\right\}_{\mathrm{i}}$ and 15 for the additional oxidation reactions $\left\{k_{0, \mathrm{ox}}, n_{\mathrm{ox}}, n_{\mathrm{O}_{2}}\right\}_{\mathrm{i}}$. Adding the fourth assumption further reduces the biomassspecific parameters to four parameters $k_{0, \mathrm{pyr}, \mathrm{i}}$ for pyrolysis and five sets $\left\{k_{0, \mathrm{ox}}, n_{\mathrm{O}_{2}}\right\}_{\mathrm{i}}$ for oxidation. It was further evaluated whether a hybrid model of a component-specific pyrolysis model and a lumped species for oxidation can describe the measured data. Assumptions 1-4 are then kept for the pyrolysis mechanism, but replaced with the following for oxidation:

5. Oxidation reactions for the four components extractives, hemicellulose, cellulose and lignin can be modelled with the same set of four kinetic parameters $\left\{E_{\mathrm{a}}, k_{0}, n_{\mathrm{ox}}, n_{\mathrm{O}_{2}}\right\}$, which are then specific to each biomass.

6. The oxidation reactions have the same activation energy for all biomasses considered (leaving 3 free parameters per biomass for oxidation).

The model based on assumptions (5) and (6) is referred to as Model I in the following, the one without those assumptions as Model II. In model I, activation energies from pure component studies were only used in the pyrolysis reactions. However, even if the oxidation reactions are unified in this way, the different volatilizable species need to be tracked individually, as their pyrolysis reactions are different.

The original mass fractions $w_{\mathrm{i}, 0}$ for volatilizable extractives, hemicellulose, lignin and cellulose, as well as char can be calculated from the composition shown in Table 1. Some estimations are made to account for the balance error in determining the composition, as well as the split between volatilizable and char-forming fraction of each component: Extractives (ethanol-soluble) and lignin (Klason) are taken as measured. Cellulose was determined by 
subtracting the hemicellulose-glucose from the total glucose. For beech, pine and sunflower, the hemicellulose-glucose was measured by acid hydrolysis. The two wood pellet samples appeared to have a carbohydrate composition somewhere in between beech (hardwood) and pine (softwood). The hemicellulose-glucose was therefore approximated with $0.02 \mathrm{~kg} / \mathrm{kg}$ for both samples (beech: $0.037 \mathrm{~kg} / \mathrm{kg}$, pine: $0.016 \mathrm{~kg} / \mathrm{kg}$ - compare Table 1). All measured glucose in wheat was assumed to be cellulose. All other organic substance, i.e. the remaining monosaccharides, the uronic acids and the hemicellulose-glucose, was lumped into the hemicellulose component. The sum of these four components is then normalized to one. Char yields from commerical cellulose, lignin and xylan samples were measured, rounded, and then used to distribute the char among the biomass components (see supporting information). For modelling, $10 \%$ of the char was associated with cellulose, $30 \%$ with hemicellulose and $60 \%$ with lignin. It was assumed that extractives are completely volatilizable. The model composition of the six biomasses, based on the above, is summarized in Table 2 .

From isothermal experiments following the same procedure as for the native biomasses, pyrolysis activation energies of $60 \mathrm{~kJ} / \mathrm{mol}$ for extractives, $120 \mathrm{~kJ} / \mathrm{mol}$ for xylan/hemicellulose, $125 \mathrm{~kJ} / \mathrm{mol}$ for lignin and $185 \mathrm{~kJ} / \mathrm{mol}$ for cellulose were obtained. Data from these measurements can be found in the supporting information.

The thermogravimetric data measured in inert atmosphere was then used to determine kinetic parameters of the four pyrolysis reactions. This was carried out in two steps. In the first step, fitting was done by simulating a large series of conversion curves for the isothermal

Table 2: Composition $w_{i, 0}$ used in the reaction kinetics model. Data calculated from composition analysis (compare Table 1). See text for discussion.

\begin{tabular}{lcccccc}
\hline & Beech wood & Pine wood & Sunflower & Wheat straw & Wood pellets I1 & Wood pellets I2 \\
\hline XTR & 0.019 & 0.090 & 0.085 & 0.038 & 0.070 & 0.070 \\
HC & 0.183 & 0.207 & 0.217 & 0.261 & 0.204 & 0.192 \\
LIG & 0.249 & 0.185 & 0.197 & 0.091 & 0.189 & 0.205 \\
CELL & 0.320 & 0.375 & 0.256 & 0.384 & 0.383 & 0.372 \\
CHAR & 0.202 & 0.141 & 0.193 & 0.184 & 0.149 & 0.155 \\
Ash & 0.027 & 0.003 & 0.052 & 0.042 & 0.006 & 0.006 \\
\hline
\end{tabular}


experiments and finding kinetic parameter sets so that the root-mean-square deviations of relative mass remaining and mass loss rate are minimized. The RMS-deviation is defined as

$$
\delta_{\varphi}=\sqrt{\frac{\sum\left(\varphi_{\exp }(t)-\varphi_{\operatorname{sim}}(t)\right)^{2}}{N}} ; \quad \varphi=\left\{m / m_{0}, d m / d t\right\}
$$

Due to numerical compensation effects, several combinations of $\left\{k_{0, \mathrm{pyr}, \mathrm{i}}, n_{\mathrm{pyr}, \mathrm{i}}\right\}$ can model the data from isothermal experiments within a similar error range. Therefore, those parameter sets which best fit the isothermal data were then checked against the data from the $5 \mathrm{~K} / \mathrm{min}$ experiments. The twenty combinations minimizing mass loss error $\left(\delta_{m / m_{0}}\right)$ and those minimizing error on the mass loss rate $\left(\delta_{d m / d t}\right)$ were compared to the constant heating rate data in this second step. That parameter set from the reduced number of combinations which minimizes the deviation in predicting the conversion rate (i.e., $\varphi=d X / d t$ in the above equation) within $373-773 \mathrm{~K}$ was then selected for each biomass. The procedure was repeated iteratively to determine uniform $n_{\mathrm{pyr}, \mathrm{i}}$ for the components, regardless of which biomass they appear in (modelling assumption 4).

The same procedure was then applied to the isothermal experiments carried out in oxidative atmosphere. The pyrolysis reactions were modelled by the kinetic parameters obtained previously. For the simpler oxidation model (model I), the fitting procedure was run iteratively to determine a common activation energy for all biomasses. The remaining kinetic parameters $\left(k_{0}, n_{\mathrm{ox}}\right.$ and $\left.n_{\mathrm{O}_{2}}\right)$ for each biomass were then found by again simulating curves with a large number of parameter combinations, and selecting those with minimal error. For the more complex scheme (model II), activation energies for oxidation of the volatilizable fractions were determined as $75 \mathrm{~kJ} / \mathrm{mol}$ for extractives, $150 \mathrm{~kJ} / \mathrm{mol}$ for xylan/hemicellulose, $120 \mathrm{~kJ} / \mathrm{mol}$ for lignin and $225 \mathrm{~kJ} / \mathrm{mol}$ for cellulose. These estimates are based on the behavior of the commercial samples when subjected to the same heating program (see supporting information). In both model I and II (i.e. single- and component oxidation model), the models for $20 \%$ and $80 \%$ oxygen were optimized simultaneously in order to determine the reaction 
order in oxygen. Again, the parameter sets that best fit the isothermal data are compared to the non-isothermal experiments, and that set which best represents the conversion rate between $373-773 \mathrm{~K}$ was chosen.

Char oxidation was assumed to be negligible in the temperature range below $523 \mathrm{~K}$. A simple kinetic calculation was carried out to check this assumption. Char in this case refers to that fraction of the material which cannot undergo further devolatilization. We assume this to be identical with the char as determined in the ultimate analysis. Branca and Di Blasi ${ }^{16,18}$ suggest a single oxidation reaction with $E_{\mathrm{a}}=185 \mathrm{~kJ} / \mathrm{mol}$ for a completely devolatilized biomass residue. This value was also used here. Pre-exponential factor and reaction order in the solid conversion were then adapted to the experimental data to match the char peaks apparent in Figure 2. The shift in char peaks from the experiments at $10 \%$ and $20 \%$ oxygen apparent in the data can be represented with a reaction order between 0 and 1. Here, the reaction order in oxygen for char was fixed at 0.5, which falls within the lower end of the range of values reported in the literature. ${ }^{14,25,46}$ It should be emphasized that optimizing the kinetics for char oxidation is not in focus of this work.

\section{Results and Discussion}

The kinetic parameters fitted to the six biomasses are found in Tables 3, 4 and 5 for the pyrolysis model, oxidation model I and oxidation model II, respectively. The same pyrolysisand char oxidation kinetics are used with oxidation models I and II. Modelled mass losses compared well to the isothermal experiments for pyrolysis and both oxidation models. Figure 3 shows the comparison for model I. Results for oxidation model II are very similar and can be found in the supporting information. Differences between the two oxidation models were more apparent when compared to the experiments with a constant $5 \mathrm{~K} /$ min heating rate (Figure 4). Results from this work show that some (but not all) parameters of the kinetic models can be obtained from pure component studies. The models are evaluated 
Table 3: Kinetic data for the pyrolysis models. Differences between biomasses are modelled by different pre-exponential factors $k_{0, \mathrm{pyr}}$. Apparent activation energies and reaction orders of the components are uniform for all biomasses, with the exception of cellulose $n_{\mathrm{pyr}}$ : Beech: 0.9, Pine: 1.1, Sunflower: 1.7, Wheat: 2.0, Wood pellets I1: 1.1, Wood pellets I2: 1.1

\begin{tabular}{lcccc}
\hline & Extractives & Hemicellulose & Lignin & Cellulose \\
\hline$E_{\text {a,pyr }}[\mathrm{kJ} / \mathrm{mol}]$ & 60 & 150 & 125 & 185 \\
$n_{\text {pyr }}[-]$ & 2.5 & 3 & 4 & $(0.9-2.0)$ \\
\hline$k_{0, \text { pyr }}\left[\mathrm{s}^{-1}\right]$ & & & & \\
$\quad$ Beech & $1.6 \times 10^{3}$ & $5.6 \times 10^{11}$ & $2.8 \times 10^{8}$ & $4.30 \times 10^{13}$ \\
Pine & $8.0 \times 10^{2}$ & $1.4 \times 10^{11}$ & $1.0 \times 10^{8}$ & $8.02 \times 10^{12}$ \\
Sunflower & $1.2 \times 10^{3}$ & $7.4 \times 10^{11}$ & $4.0 \times 10^{7}$ & $7.94 \times 10^{13}$ \\
Wheat & $1.0 \times 10^{3}$ & $3.2 \times 10^{11}$ & $4.0 \times 10^{8}$ & $7.47 \times 10^{13}$ \\
Wood pellets I1 & $4.0 \times 10^{2}$ & $2.6 \times 10^{11}$ & $1.2 \times 10^{8}$ & $1.36 \times 10^{13}$ \\
Wood pellets I2 & $6.0 \times 10^{2}$ & $1.4 \times 10^{11}$ & $1.2 \times 10^{8}$ & $1.06 \times 10^{13}$ \\
\hline
\end{tabular}

Table 4: Oxidation model I: kinetics for oxidation of a lumped volatilizable component and char. The same char kinetics are used in oxidation model II.

\begin{tabular}{|c|c|c|c|c|c|c|}
\hline \multirow{3}{*}{$E_{\mathrm{a}}[\mathrm{kJ} / \mathrm{mol}]$} & \multicolumn{3}{|c|}{ Extr./Hemicell./Lig./Cell } & \multicolumn{3}{|c|}{ Char } \\
\hline & \multicolumn{3}{|c|}{130} & \multicolumn{3}{|c|}{185} \\
\hline & $\begin{array}{c}k_{0} \\
{\left[\mathrm{~s}^{-1}\right]}\end{array}$ & $\begin{array}{c}n_{\text {ox }} \\
{[-]}\end{array}$ & $\begin{array}{c}n_{\mathrm{O}_{2}} \\
{[-]}\end{array}$ & $\begin{array}{c}k_{0} \\
{\left[\mathrm{~s}^{-1}\right]}\end{array}$ & $\begin{array}{c}n_{\mathrm{ox}} \\
{[-]}\end{array}$ & $\begin{array}{c}n_{\mathrm{O}_{2}} \\
{[-]}\end{array}$ \\
\hline Beech & $2.00 \times 10^{7}$ & 2.2 & 0.45 & $5.7 \times 10^{9}$ & 1.0 & 0.5 \\
\hline Pine & $1.04 \times 10^{7}$ & 1.25 & 0.40 & $5.0 \times 10^{8}$ & 0.55 & 0.5 \\
\hline Sunflower & $1.62 \times 10^{7}$ & 2.5 & 0.50 & $5.0 \times 10^{8}$ & 0.65 & 0.5 \\
\hline Wheat & $1.49 \times 10^{7}$ & 1.6 & 0.50 & $5.7 \times 10^{9}$ & 1.0 & 0.5 \\
\hline Wood pellets I1 & $7.52 \times 10^{6}$ & 2.2 & 0.45 & $1.1 \times 10^{9}$ & 0.8 & 0.5 \\
\hline Wood pellets I2 & $5.60 \times 10^{6}$ & 2.5 & 0.45 & $4.2 \times 10^{8}$ & 0.5 & 0.5 \\
\hline
\end{tabular}


Table 5: Model II: kinetic data for the component-dependent oxidation model. Differences between biomasses are modelled by different pre-exponential factors $k_{0, \text { ox }}$ and reaction orders in oxygen $n_{\mathrm{O}_{2}}$. Apparent activation energies and reaction orders of the components are uniform for all biomasses, with the exception of cellulose $n_{\text {ox }}$ : Beech: 2.2, Pine: 0.6, Sunflower: 3.7, Wheat: 1.8, Wood pellets I1: 0.9, Wood pellets I2: 1.0. Char kinetic data is the same as in Table 4

\begin{tabular}{lccccc}
\hline & Extractives & Hemicellulose & Lignin & Cellulose & Char \\
\hline$E_{\mathrm{a}, \mathrm{ox}}[\mathrm{kJ} / \mathrm{mol}]$ & $(75)$ & 200 & 120 & 225 & 185 \\
$n_{\mathrm{ox}}[-]$ & $(1)$ & 1.6 & 2.5 & $(0.6-3.7)$ & $(0.5-1.0)$ \\
\hline$k_{0, \mathrm{ox}}\left[\mathrm{s}^{-1}\right]$ & & & & & \\
$\quad$ Beech & 0 & $2.45 \times 10^{15}$ & $1.55 \times 10^{6}$ & $2.5 \times 10^{13}$ & $5.7 \times 10^{9}$ \\
Pine & 0 & $5.0 \times 10^{14}$ & $1.0 \times 10^{5}$ & $5.5 \times 10^{12}$ & $5.0 \times 10^{8}$ \\
Sunflower & 0 & $6.5 \times 10^{14}$ & $3.9 \times 10^{5}$ & $2.5 \times 10^{13}$ & $5.0 \times 10^{8}$ \\
Wheat & 0 & $1.0 \times 10^{15}$ & $6.7 \times 10^{5}$ & $4.0 \times 10^{13}$ & $5.7 \times 10^{9}$ \\
Wood pellets I1 & 0 & $4.0 \times 10^{14}$ & $1.0 \times 10^{5}$ & $6.5 \times 10^{12}$ & $1.1 \times 10^{9}$ \\
Wood pellets I2 & 0 & $8.5 \times 10^{14}$ & $1.0 \times 10^{5}$ & $4.5 \times 10^{12}$ & $4.2 \times 10^{8}$ \\
\hline$n_{\mathrm{O}_{2}}[-]$ & & & & & \\
Beech & - & 0.4 & 0.5 & 1.1 & 0.5 \\
Pine & - & 0.4 & 0.6 & 1.1 & 0.5 \\
Sunflower & - & 0.5 & 0.7 & 1.1 & 0.5 \\
Wheat & - & 0.5 & 0.7 & 1.1 & 0.5 \\
Wood pellets I1 & - & 0.5 & 0.6 & 1.1 & 0.5 \\
Wood pellets I2 & - & 0.3 & 0.7 & 1.1 & 0.5 \\
\hline
\end{tabular}




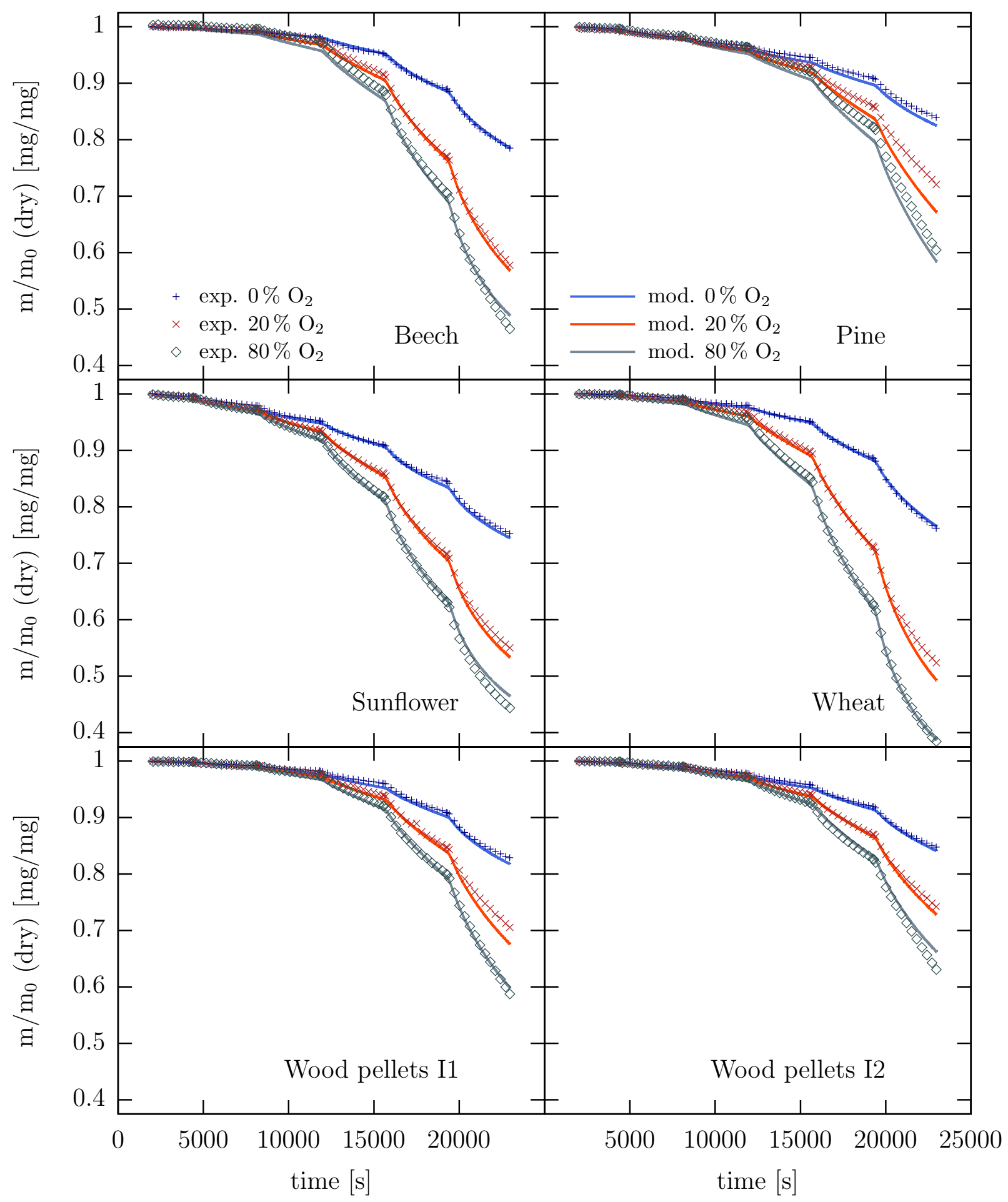

Figure 3: Oxidation model I: comparison of isothermal experiments and models for six biomasses, assuming that the oxidation of hemicellulose, cellulose, lignin and extractives can be modelled by the same set of kinetic data. Kinetic parameters are listed in Tables 3 and 4. 


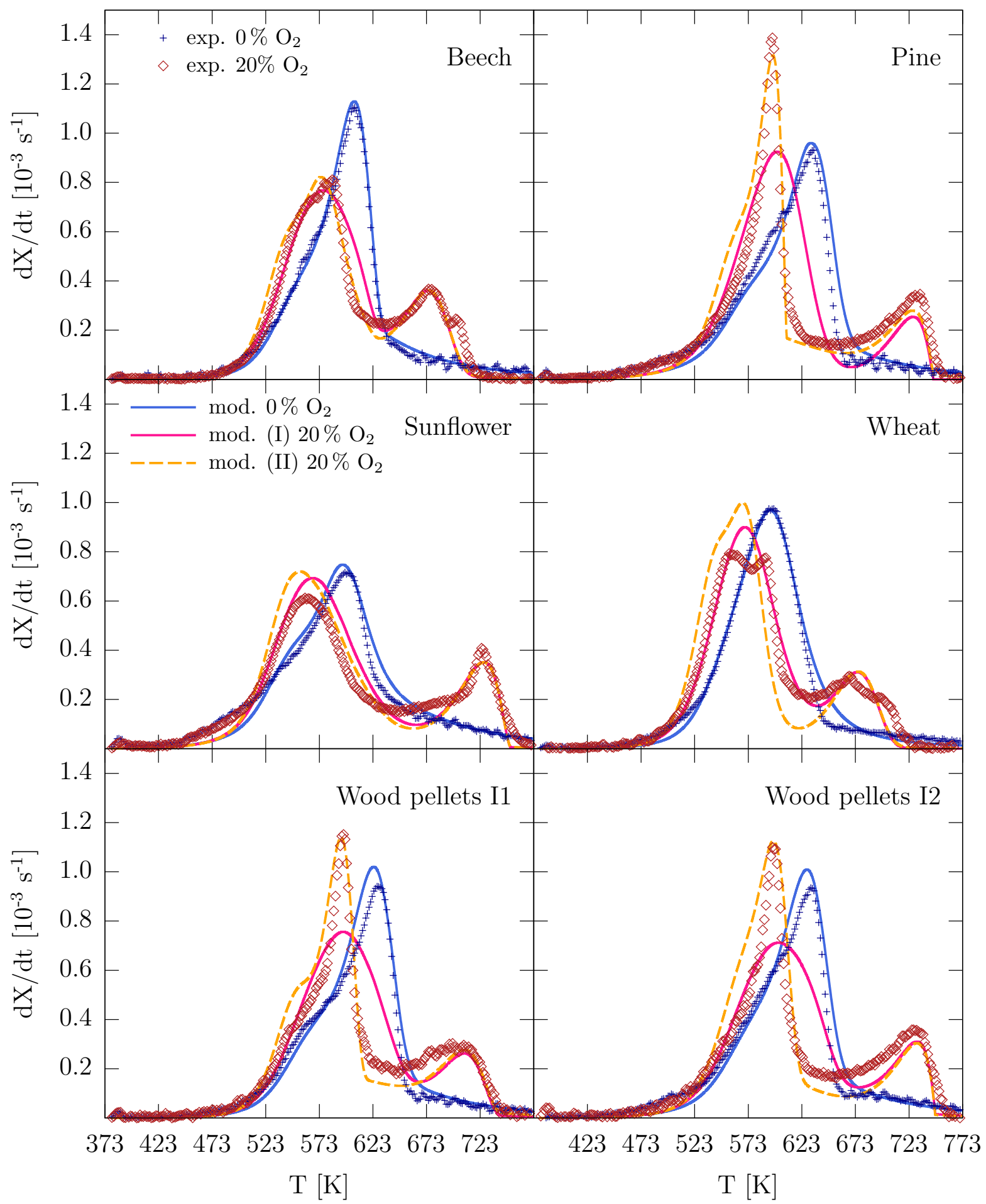

Figure 4: Oxidation model I and II: comparison of experiments at constant heating rate and models for six biomasses, assuming uniform (model I) and separate oxidation kinetics (model II) of hemicellulose, cellulose, lignin and extractives. Symbols represent experimental data, lines are modelled data. Kinetic parameters are listed in Tables 3, 4 and 5. 
for numerical, rather than physical or chemical accuracy - i.e., the model representations of extractives, hemicellulose, lignin and cellulose cannot fully capture the complex behavior of these components as they are found in the biomasses. Additionally, structural influences and component interactions are neccessarily convoluted in the kinetic parameters in the proposed scheme of independent and parallel reactions.

Results from modelling pyrolysis and oxidation kinetics are discussed separately below.

\subsection{Pyrolysis kinetics}

The kinetic parameters found could explain the experimental data both for the isothermal experiments and those at $5 \mathrm{~K} / \mathrm{min}$. Table 6 lists the scaled root-mean-square deviations between model and experiment. Scaled deviations between model and measurement are similar in magnitude to the scaled deviations among repeated experiments (compare section 2.2). The values found for the activation energies are moreover in good agreement with those found in the literature (e.g., as reviewed in ${ }^{35,47}$ ).

An initial loss of mass (423-443 K) could be associated with high amounts of extractives in pine and sunflower (both $9 \%$ ), although this effect was absent in both wood pellet samples (each $7 \%$ extractives), compare Figures 1, 3 and Table 1 . The model predicts that extrac-

Table 6: Scaled root-mean-square deviations $\left(\delta_{\mathrm{S}, \varphi}\right)$ between modelled and measured data in inert atmosphere. "Isothermal" refers to the stepwise isothermal experiments, "ramp" to those at constant heating rate $5 \mathrm{~K} / \mathrm{min}$.

\begin{tabular}{lccccc}
\hline & \multicolumn{2}{c}{$\delta_{\mathrm{S}}\left(\mathrm{m} / \mathrm{m}_{0}\right)$} & & \multicolumn{2}{c}{$\delta_{\mathrm{S}}(d X / d t)$} \\
\cline { 2 - 3 } \cline { 6 - 6 } Experiment & $\begin{array}{c}\text { isothermal } \\
{[\%]}\end{array}$ & $\begin{array}{c}\text { ramp } \\
{[\%]}\end{array}$ & & $\begin{array}{c}\text { isothermal } \\
{[\%]}\end{array}$ & $\begin{array}{c}\text { ramp } \\
{[\%]}\end{array}$ \\
\hline Beech & 0.84 & 3.60 & & 10.23 & 2.22 \\
Pine & 4.44 & 6.51 & & 10.33 & 7.16 \\
Sunflower & 1.83 & 5.13 & & 12.05 & 6.07 \\
Wheat straw & 2.40 & 4.39 & & 9.64 & 3.62 \\
Wood pellets I1 & 5.13 & 4.95 & & 12.10 & 5.31 \\
Wood pellets I2 & 4.75 & 5.68 & & 15.61 & 6.38 \\
\hline
\end{tabular}


tives are pyrolyzed to a large degree (70-90\%) in the isothermal experiments. However, extractives make up only a small part of the biomasses. In the full temperature range of the isothermal experiments, $423-523 \mathrm{~K}$, pyrolysis of the six biomasses is dominated primarily by the decomposition of hemicellulose (25-65\% conversion) and, secondly, of lignin (15-25\%). An exception is sunflower husk pellets, where the model predicts a slightly lower mass loss of lignin compared to cellulose $(6 \%$ and $10 \%$, respectively). Modelled mass losses of the cellulose component are otherwise low in this temperature range (1-11\%). Additionally, pure cellulose did not show any significant pyrolytic conversion below $503 \mathrm{~K}$ (see supporting information). In the experiments at $5 \mathrm{~K} / \mathrm{min}$ heating rate, a near-complete devolatilization of all biomass samples is observed. This is also captured in the model, as conversion rates approach zero at $773 \mathrm{~K}$ in Figure 4.

The activation energy found in the xylan experiments, $125 \mathrm{~kJ} / \mathrm{mol}$, does not represent the hemicellulose components of all biomasses in the $5 \mathrm{~K} / \mathrm{min}$ constant-heating-rate experiments very well. An increased value of $150 \mathrm{~kJ} / \mathrm{mol}$ provides a better agreement between model and measurement. This can be justified by the inhomogeneous nature of hemicellulose (compare Table 1), which varies among plant species. ${ }^{37,48,49}$ Thermal behavior of hemicelluloses may differ substantially, depending on their composition. ${ }^{37,50-52}$ Xylan is thermally less stable than most other hemicelluloses. ${ }^{51}$ A higher activation energy for the heterogeneous hemicelluloses of the six biomasses is therefore plausible.

Owing to its low conversion in the isothermal experiments, the free parameters of the cellulose component in the pyrolysis model $\left(k_{0, \mathrm{pyr}, \mathrm{CELL}}\right.$ and $\left.n_{\mathrm{pyr}, \mathrm{CELL}}\right)$ could not be reliably established from the isothermal experiments. Kinetic parameters were therefore adapted to match the peak seen in the conversion rate/temperature plots (Figures 1 and 4). Inorganic elements present in the biomass are known to catalyze pyrolysis of the cellulose component. ${ }^{36,53}$ For several biomasses, it has been shown that the temperature of peak conversion rate is decreased with increasing potassium content. ${ }^{36,54,55}$ The data for the biomasses investigated here agree with these reported trends, and this can be used to calculate the 
pre-exponential factors $k_{0, \text { pyr,CELL }}$ of cellulose pyrolysis from the potassium content. For an activation energy of $185 \mathrm{~kJ} / \mathrm{mol}$, the pre-exponential factors can be linearly correlated with the potassium mass fraction $w_{\mathrm{K}}$ by

$$
k_{0, \mathrm{pyr}, \mathrm{CELL}}=\left(9.34 \times 10^{15} \cdot w_{\mathrm{K}}+2.37 \times 10^{12} \pm 2.29 \times 10^{12}\right) \cdot \mathrm{s}^{-1}
$$

to reproduce the temperatures of peak decomposition rate. Details can be found in the supporting information. The apparent reaction order in the solid was then set to match the value of the peak decomposition rate. Catalytic effects of inorganic elements have also been used to model hemicellulose pyrolysis. ${ }^{56}$ In our experiments, catalytic effects seemed to be smaller than compositional effects for hemicellulose pyrolysis. The inorganic content could therefore only be used to predict cellulose kinetic parameters, but not those of the other components.

The different biomasses can be compared in an Arrhenius plot, Figure 5. The sum of the modelled rate constants $k_{\mathrm{i}}$ is plotted over $1 / T$, i.e.

$$
k_{\mathrm{tot}}(T)=\sum_{\mathrm{i}} k_{0, \mathrm{i}} \cdot \exp \left(-\frac{E_{\mathrm{a}, \mathrm{i}}}{R \cdot T}\right) ; \quad i=\{\mathrm{XTR}, \mathrm{HC}, \mathrm{LIG}, \mathrm{CELL}\}
$$

In the above expression, $k_{\text {tot }}$ does not take the degree of conversion into account, since this depends on the time-temperature history of the samples. The slope of a curve on an Arrhenius plot is proportional to $-E_{\mathrm{a}} / R$, i.e., the thermal behavior of the biomasses can be compared in this way. The plot shows a high-temperature and a low-temperature regime for all six biomasses, with a transition region at ca. 450-550 K. At temperatures below the transition region, the slope of the curves approach that of the extractive component $(60 \mathrm{~kJ} / \mathrm{mol})$. For temperatures above the transition region, the slope of the curve roughly corresponds to that given by the hemicellulose component $(150 \mathrm{~kJ} / \mathrm{mol})$, and would asymptotically approach that of the cellulose component if extrapolated further (above $\approx 1000 \mathrm{~K}$ ). In practical experiments, the hemicellulose is depleted already at lower temperatures, so the measured rates 


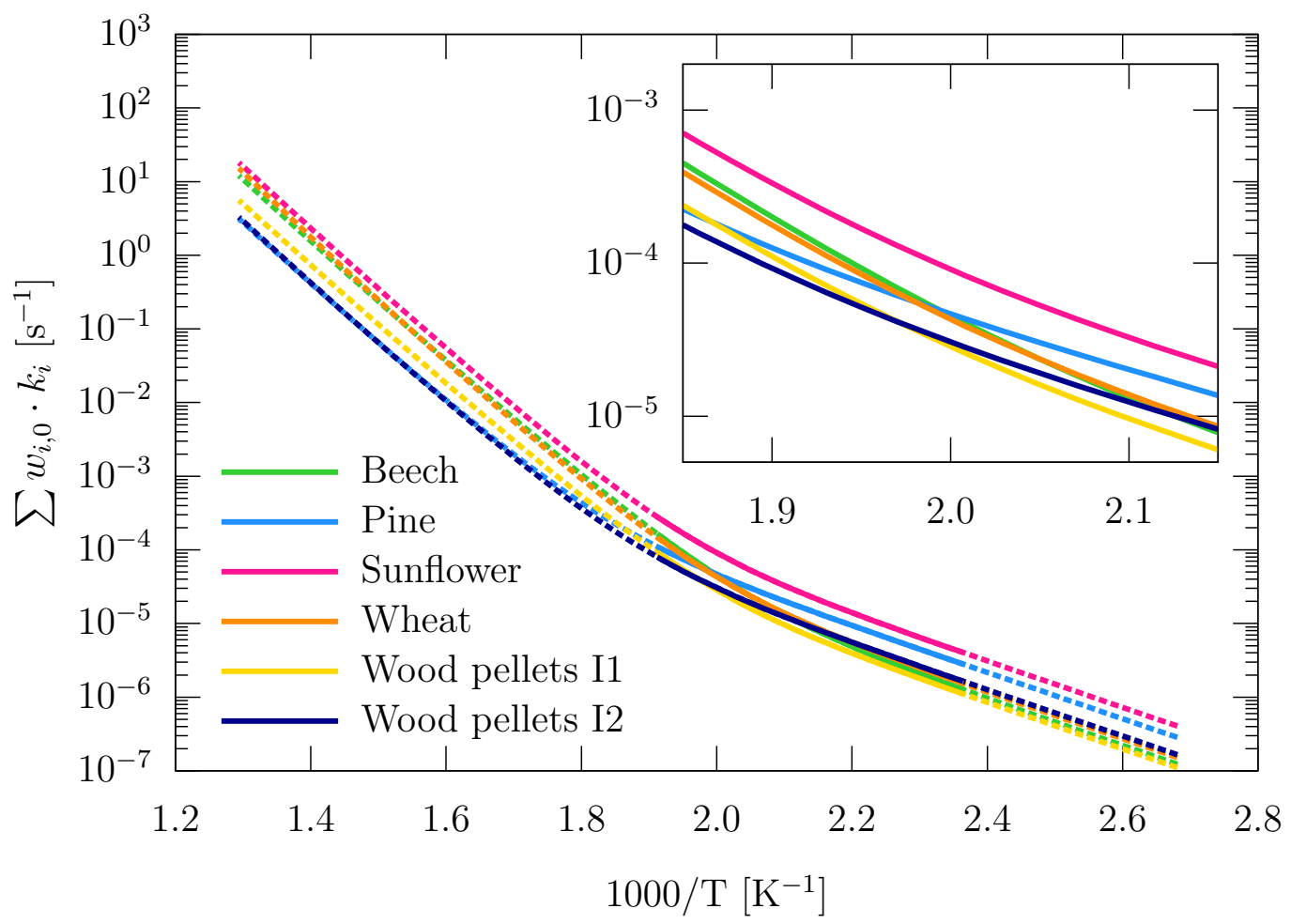

Figure 5: Arrhenius plot of the pyrolysis models. Solid lines represent the interval 423$523 \mathrm{~K}$ of the stepwise isothermal experiments. The dashed lines extend to $373 \mathrm{~K}$ and $773 \mathrm{~K}$, respectively, covering the range of the constant heating rate experiments. The inset magnifies the region $465-540 \mathrm{~K}$. 
become dominated by cellulose kinetics around $600 \mathrm{~K}$ (see e.g. ${ }^{18,35,40,57}$ ). By comparison wih Figure 2, the transition region $(450-550 \mathrm{~K})$ is not well resolved in experiments with constant heating rate of $5 \mathrm{~K} / \mathrm{min}$ or above, which make up the majority of TG-data reported in the literature. This may explain why models fitted to such data do not explain kinetics at these temperatures (and below) very well. The plot also illustrates the relative reactivity of the six biomasses. Sunflower has the highest reaction rate over the entire temperature range, while the reactivity of wheat increases most over the range evaluated. This compares well to experimental data (Figures 1 and 2). Pine appears more reactive at low temperatures and less reactive at high temperatures. This can be explained by its high amount of extractives (low temperature behavior, $<500 \mathrm{~K}$ ) on one hand, and by the low reactivity of its hemicellulose and cellulose components (see $k_{0, \text { pyr }}$ in Table 3 ) on the other (high temperature behavior, $>550 \mathrm{~K})$. In comparison, wheat has a high content of cellulose and a low content of lignin, resulting in a steeper gradient (high activation energy of cellulose component) at the high temperature end of the graph than those seen for other biomasses. The model behavior in the transition zone is explained by both the composition and the reactivity of the individual components. The analysis also shows that no single property of the biomass determines its pyrolysis behavior over the entire temperature range. Rather, rates appear to change from being extractives-dominated, to a hemicellulose-controlled range, and finally to a combined cellulose-hemicellulose controlled regime.

\subsection{Oxidation kinetics}

Both oxidation models I and II are in agreement with data from the stepwise isothermal experiments at $20 \%$ and $80 \%$ oxygen concentration. In model I, an apparent activation energy of $130 \mathrm{~kJ} / \mathrm{mol}$ describes the oxidation of the volatile fractions of extractives, hemicellulose, lignin and cellulose in the temperature range of $423-523 \mathrm{~K}$. The corresponding reaction orders in oxygen are between 0.4 and 0.5 (model I, Table 4). Similar rates are found in this region as the sum of hemicellulose, lignin and cellulose kinetics (model II, Table 5). 
Both oxidation models give a quality of fit similar to the pyrolysis models, where the quality of fit is measured by the scaled root-mean-square deviations between model and experiment (see supporting information). From the standpoint of numerical accuracy, there is no reason to prefer one model over the other in describing the TGA-experiments. The reason why model II, despite its larger number of parameters, does not give a significantly better fit may be due to the constraints placed on some of these parameters - most notably, setting the activation energies to constant values derived from pure component measurements.

The most apparent difference between models I and II is how the overlap between hemicellulose and cellulose oxidation is described at temperatures within 520-670 K, Figure 4. Model I predicts a flatter conversion rate profile, with lower peak rates (pine, wood pellets) and a more smooth drop in coversion rates. The higher maximum conversion rates of pine and both wood pellets $\left(0.0014 \mathrm{~s}^{-1}, 0.0012 \mathrm{~s}^{-1}\right)$ can be modelled by initially low cellulose oxidation rates, that rapidly accelerate at higher temperatures $(>550 \mathrm{~K})$. However, the lower reactivity of cellulose at temperatures below $\approx 550 \mathrm{~K}$ is compensated by a higher hemicellulose reactivity to model the mass loss observed in the stepwise isothermal experiment (model II). This leads to an over-estimation of conversion rates between 520-570 K (Figure 4, especially pronounced for both wood pellet samples and pine). The onset behavior $(\approx 450-520 \mathrm{~K})$ of sunflower in the $5 \mathrm{~K} /$ min experiments is only approximated by the pyrolysis model and both oxidation models. This could possibly be traced to the parameters of the hemicellulose model.

Differences in modelling the individual components also appear in the stepwise isothermal experiments, although nearly the same total mass loss is predicted by both models for each biomass. The general trend is that model I predicts higher conversion of the cellulose component and a lower hemicellulose conversion up to $523 \mathrm{~K}$, compared to model II. In model I, conversion of hemicellulose is within $45-70 \%$ for the six biomasses, lignin within $30-55 \%$ and cellulose 25-55\%. In comparison, model II predicts 55-90\% conversion for hemicellullose, $20-65 \%$ for lignin and 5-25\% for cellulose. In general, the conversion of the components is 
qualitatively proportional to the total conversion for the six biomasses, i.e., biomasses with a high degree of conversion of hemicellulose also have high degrees of conversion of lignin and cellulose. More details can be seen in the supporting information. Predicted conversion of extractives does not differ much between the two oxidation models and is in the range of $70-90 \%$ for the six biomasses. The values given refer to conversion as the combined effect of pyrolysis and oxidation.

The apparent activation energy for oxidation found in model I $(130 \mathrm{~kJ} / \mathrm{mol})$ falls in the middle of the range of values reported in the literature $(90-210 \mathrm{~kJ} / \mathrm{mol})^{6,10,11}$. It should be noted that these literature values were derived without separating oxidation and pyrolysis reactions. Activation energies found for model II are also comparable to those reported in the literature: $70-294 \mathrm{~kJ} / \mathrm{mol}$ for hemicellulose, $54-289 \mathrm{~kJ} / \mathrm{mol}$ for lignin and $70-295 \mathrm{~kJ} / \mathrm{mol}$ for cellulose. ${ }^{13,14,17,23-25,45}$ A direct comparison is difficult owing to the different reaction models chosen by different authors. As for the pyrolysis model, the apparent activation energy for hemicellulose $(200 \mathrm{~kJ} / \mathrm{mol})$ was set higher than that of the xylan experiments $(150 \mathrm{~kJ} / \mathrm{mol})$. Apparent reaction orders in oxygen of the cellulose component are slightly $>1$, which is somewhat unexpected, and probably a result of the numeric fitting routine. For model II, no contribution of extractives oxidation was found. This will be discussed further below.

The oxidation models can be compared using the same type of Arrhenius plot as for the pyrolysis experiments, as shown in Figure 6. Both models are evaluated as combined rates of oxidation and pyrolysis reactions. Similar to the pyrolysis model, a transition region around $450-550 \mathrm{~K}$ can be seen. In the low temperature range of the plot $(<450 \mathrm{~K})$, the overall apparent rate is mainly dependent on the pyrolysis of extractives $\left(E_{\mathrm{a}}=60 \mathrm{~kJ} / \mathrm{mol}\right)$. The contribution of the oxidation reaction is more pronounced from $500 \mathrm{~K}$ and upwards (compare Figure 5), which is also where predictions of the two oxidation models begin to diverge. Model II generally predicts higher rates $k_{\text {tot }}$, while the order of biomasses with respect to reactivity is similar in both models over a broad temperature range (with sunflower, wheat and beech the most, and wood pellets $\mathrm{I} 2$ and pine the least reactive above $525 \mathrm{~K}$ ). In comparison 

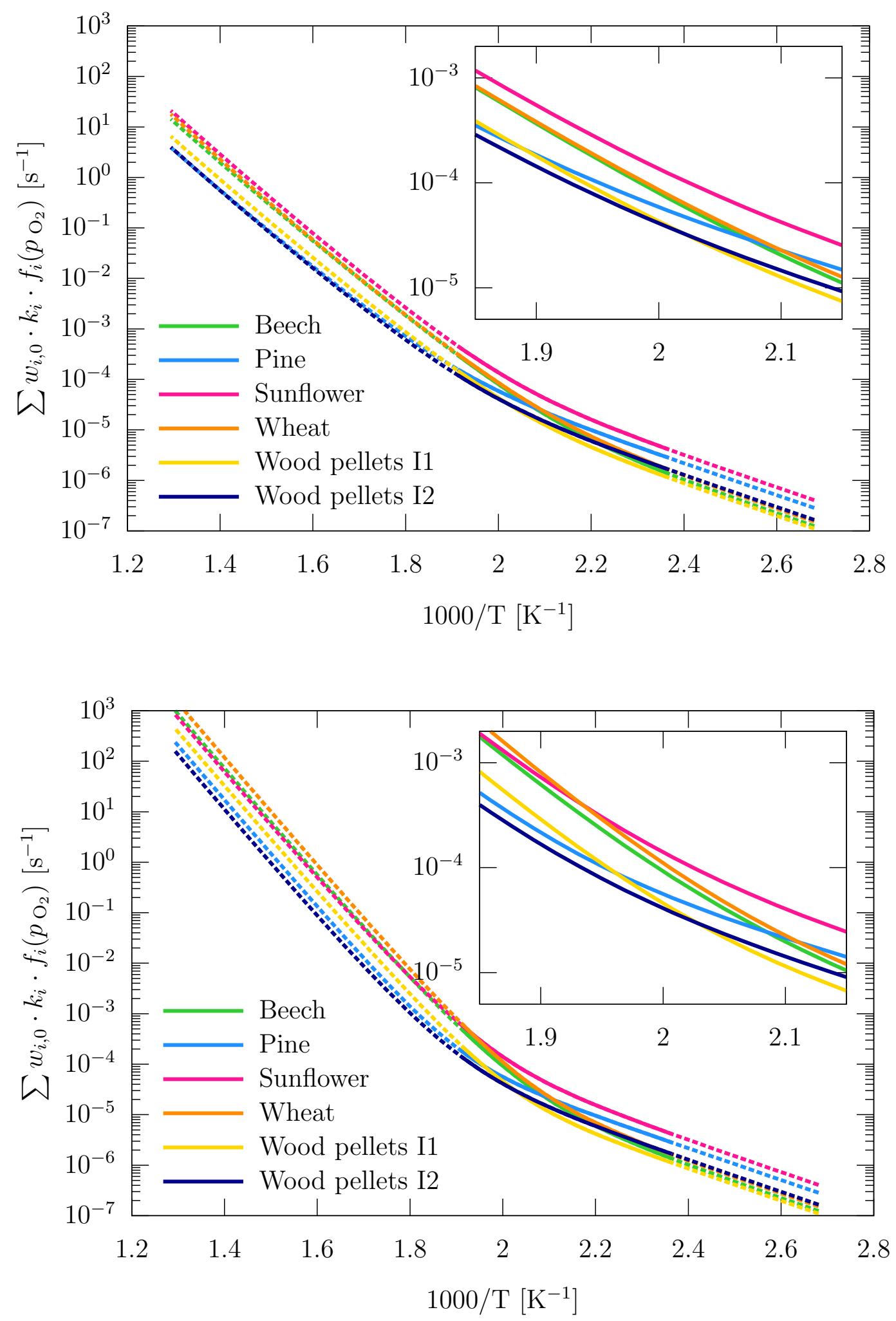

Figure 6: Arrhenius plot of the oxidation models for model I (top) and II (bottom), evaluated at $p_{\mathrm{O}_{2}}=20 \mathrm{kPa}$. Solid lines represent the interval $423-523 \mathrm{~K}$ of the stepwise isothermal experiments. The dashed lines extend to $373 \mathrm{~K}$ and $773 \mathrm{~K}$, respectively, covering the range of the constant heating rate experiments. The insets magnify the region $465-540 \mathrm{~K}$. 
with measured data (Figures 1 and 2), conversion rates of beech and wheat exceed those of sunflower at higher temperature (>503 K in Figure 1). This is also reflected in the preexponential factors in both oxidation models (Tables 4 and 5), but not seen in the Arrhenius plot for model I, and visible only for temperatures above $550 \mathrm{~K}$ in model II. For model II, the rates $k_{\text {tot }}$ are strongly influenced by the pre-exponential factor for oxidation of cellulose (Table 5) above $525 \mathrm{~K}$, so that beech is modelled most reactive at higher temperatures $(>625 \mathrm{~K})$. For model I, the pyrolysis kinetics of cellulose determine the order of biomasses on the Arrhenius plot. The contribution of the global oxidation reaction to the modelled rate is weak, owing to its lower activation energy $\left(E_{\mathrm{ox}}=130 \mathrm{~kJ} / \mathrm{mol}\right.$, compared to $E_{\mathrm{pyr}, \mathrm{CELL}}=185 \mathrm{~kJ} / \mathrm{mol}$ and $\left.E_{\mathrm{pyr}, \mathrm{HC}}=150 \mathrm{~kJ} / \mathrm{mol}\right)$.

Conversion-free rates $k_{\text {tot }}$ can also be calculated from published reaction mechanisms for pine. ${ }^{13,14,17}$ The model presented in ${ }^{14}$ gives $k_{\text {tot }}$-rates very similar to model I. The model presented in ${ }^{13}$ for pine is also in fair agreement with our model II from temperatures of $500 \mathrm{~K}$ and above, and gives rates $k_{\text {tot }}$ that are slightly higher below this temperature. Evaluating a third model ${ }^{17}$ gave significantly higher rates than the ones found here.

The absence of extractives oxidation in model II was unexpected, as spontaneous oxidation of extractives can occur at very low temperatures $(303-323 \mathrm{~K})^{1,2}$ and with low activation energies (as low as 55-60 kJ/mol). ${ }^{1,7}$ Reactions at very low temperatures $(<400 \mathrm{~K}$ ) and with low activation energies are difficult to detect in the experimental program used, however. As briefly discussed above, the rate $k_{\text {tot }}$ becomes increasingly dominated by higher activation energy reactions (especially of hemicellulose) with higher temperatures, and reactions with $E_{\mathrm{a}}<60 \mathrm{~kJ} / \mathrm{mol}$ are drowned out. At the low temperature stage of the isothermal experiments $(423 \mathrm{~K})$, the lowest measurable reaction rates were in order of $10^{-6} \mathrm{~s}^{-1}$, and this is also represented in the model (compare Figures 5 and 6). At this point, mass loss due to pyrolysis and oxidation could not be distinguished (Figure 3). Oxidation of extractives would therefore require significantly higher rates than those of their pyrolysis to be visible in the experiments. Moreover, extractives could also have been partially evaporated rather 
than pyrolyzed or oxidized in the experiments. Boiling points of C8:0-C18:0 fatty acids are in a range of 510-630 K, with corresponding enthalpies of evaporation $50-122 \mathrm{~kJ} / \mathrm{mol}$.

Similar to the pyrolysis kinetics, no clear correlation between composition (Table 1) and reactivity (Figure 6) was found. One trend that can be seen is that biomasses rich in potassium (sunflower, wheat; and to a lesser extent, beech) are more reactive at temperatures above $\approx 500 \mathrm{~K}$ than those with low amounts of alkali and alkaline earth metals (pine, both wood pellet samples). This tendency agrees with the trend observed for pyrolysis. Qualitatively, the same observation as for pyrolysis can be made: total reaction rates are dominated by (pyrolysis) extractive kinetics at low temperatures $(<450 \mathrm{~K})$ and become increasingly controlled by hemicellulose and cellulose at higher temperatures (model II) or the combination of oxidation of the lumped volatilizable species and pyrolysis of hemicellulose and cellulose (model I). The role of lignin is difficult to distinguish, and its reactions appear to take place in the background. Consequentially, the kinetic parameters determined for the lignin component in model II (Table 5) are very similar to the global parameters determined in model I (Table 4) for the lumped volatilizable component.

\section{Conclusions}

Owing to its high reactivity at low temperatures, biomass may self-heat and spontaneously ignite when kept or processed in hot environments $(>423 \mathrm{~K})$ such as power plant mills. Thermogravimetric analysis of stepwise isothermal experiments at $423-523 \mathrm{~K}$ was carried out for six biomasses: two wood species (beech, pine), two commercial wood pellet samples, and two agricultural residues (wheat straw and pelletized sunflower husks). These data were modelled by a reaction scheme considering oxidation and pyrolysis separately, and by modelling biomass as the sum of volatilizable hemicellulose, cellulose, lignin and extractives, as well as a non-volatilizable, combustible fraction (char), and ash as inert component. The pyrolysis model (Table 3) of four volatilizable components was in good agreement with 
measured data in nitrogen atmosphere. The mechanisms also compared favorably to further experiments carried out between $373-773 \mathrm{~K}$ at a constant heating rate of $5 \mathrm{~K} / \mathrm{min}$.

For the oxidation process, two different approaches were considered. In the first model (model I, Table 4), the volatilizable components were treated as a lumped species, i.e. modelled by the same oxidation kinetic parameters. In an alternative model (model II, Table 5), the oxidation of volatilizable hemicellulose, cellulose, lignin and extractives were treated separately. Both models compared well with experimental data for stepwise isothermal experiments at 423-523 K in $20 \%$ and $80 \%$ oxygen atmosphere. Oxidation (globally, i.e. for the lumped volatilizable component) had an apparent reaction order in oxygen of 0.4-0.5. The oxidation models could with fair accuracy also be applied to experiments at 373-773 K with a constant heating rate of $5 \mathrm{~K} /$ min under $10 \%$ and $20 \%$ oxygen atmosphere. Differences between the two oxidation models were mainly found in the predicted degree of conversion of hemicellulose and cellulose. For the global mass loss in the temperature range of $423-523 \mathrm{~K}$, the simpler oxidation model is considered as sufficiently accurate, and considering oxidation of the components separately does not offer an advantage.

Some simplifications to the oxidation and pyrolysis models were possible. It was found that activation energies for the biomass components could be set to the same value, regardless of which biomass they appear in. In this work, activation energies were fixed to values derived from experiments on commercial cellulose, lignin and xylan samples. This is to be understood as a numerically, rather than physically correct description of the mass loss kinetics. Values found for activation energies were consistent with those published in the literature. The models developed here mainly differ from previous work in the description of the low temperature range $(423-523 \mathrm{~K})$. This could especially be seen in a change from a low-temperature regime $<450 \mathrm{~K}$, which appeared dominated by extractive kinetics, to a higher temperature regime $>500 \mathrm{~K}$, which is controlled mainly by reactions of hemicellulose and, to a lesser extent, by cellulose (Figures 5 and 6). Biomass rich in extractives (sunflower, pine) correspondingly appeared most reactive at the lower end of the investigated 
temperature range, whereas biomass with large potassium content (possibly catalyzing cellulose conversion) showed larger mass loss rates (wheat, sunflower) at the upper end of the temperature range.

The kinetic models presented here can be used in simulations of low temperature conversion processes, especially self-heating, self-ignition and smoldering combustion of pulverized biomass. While some trends could be observed, there does not appear to be a strong coupling between any single component and the observed reactivity of the different biomasses. Further research combining composition information and kinetic parameters may be able to shed more light on the relation between the two.

\section{Supporting Information}

The supplementary material contains a comparison of two models from the literature with measured data from this work, showing that models fitted to classical TGA-experiments do not represent low temperature mass loss very well. It further contains: an assessment of kinetic control in the TG-experimnets; data from cellulose, lignin, xylan and rapeseed oil experiments; as well as additional information on the modelled conversion of components for the biomasses used.

\section{Acknowledegements}

The authors thank Ørsted A/S and Energinet for financial support of this work. Tareq Abdulrahman is thanked for assisting in the TGA measurements. Marvin Masche is acknowledged for providing the wood pellet samples and additional analysis data. 


\section{Symbols and abbreviations}

\begin{tabular}{|c|c|c|}
\hline symbol & quantity & base units \\
\hline $\mathrm{Bi}$ & Biot number & - \\
\hline$E_{\mathrm{a}}$ & apparent activation energy & $\mathrm{J} \mathrm{mol}^{-1}$ \\
\hline$k$ & reaction rate & $\mathrm{s}^{-1}$ \\
\hline$k_{0}$ & pre-exponential factor & $\mathrm{s}^{-1}$ \\
\hline$m$ & mass & $\mathrm{kg}$ \\
\hline$N$ & number of data points & - \\
\hline$n$ & apparent reaction order & - \\
\hline$p$ & pressure & $\mathrm{Pa}$ \\
\hline$R$ & universal gas constant & $\mathrm{J} \mathrm{mol}^{-1} \mathrm{~K}^{-1}$ \\
\hline$T$ & temperature & $\mathrm{K}$ \\
\hline$t$ & time & $\mathrm{s}$ \\
\hline$w$ & mass fraction & $\mathrm{kg} \mathrm{kg}^{-1}$ \\
\hline$X$ & conversion & - \\
\hline$\delta_{\varphi}$ & deviation of $\varphi$ & units of $\varphi$ \\
\hline$\delta_{\mathrm{S}, \varphi}$ & scaled deviation of $\varphi$ & - \\
\hline \multicolumn{3}{|l|}{ indices } \\
\hline 0 & initial & \\
\hline $\exp$ & experiment & \\
\hline $\mathrm{f}$ & final & \\
\hline ox & oxidation & \\
\hline pyr & pyrolysis & \\
\hline ref & reference & \\
\hline $\operatorname{sim}$ & simulation & \\
\hline
\end{tabular}




$\begin{array}{ll}\text { vol } & \text { volatilizable } \\ \text { CELL } & \text { cellulose } \\ \text { HC } & \text { hemicellulose } \\ \text { LIG } & \text { lignin } \\ \text { XTR } & \text { extractives }\end{array}$

abbreviations

RMS root-mean-square

TGA thermo-gravimetric analysis

\section{References}

(1) Guo, W.; Trischuk, K.; Bi, X.; Lim, C. J.; Sokhansanj, S. Measurements of wood pellets self-heating kinetic parameters using isothermal calorimetry. Biomass and Bioenergy 2014, 63, 1-9.

(2) Rahman, M. A.; Hopke, P. K. Mechanistic Pathway of Carbon Monoxide Off-Gassing from Wood Pellets. Energy and Fuels 2016, 30, 5809-5815.

(3) Birkby, C.; Brown, J.; Street, P. J. The early detection of mill fires by monitoring for carbon monoxide. Combustion 1973, 45, 38-42.

(4) Ren, T. X.; Edwards, J. S.; Clarke, D. Adiabatic oxidation study on the propensity of pulverised coals to spontaneous combustion. Fuel 1999, 78, 1611-1620.

(5) Savolainen, K. Co-firing of biomass in coal-fired utility boilers. Applied Energy 2003, 74, 369-381. 
(6) Stamm, A. J. Thermal Degradation of Wood and Cellulose. Industrial and Engineering Chemistry 1956, 48 .

(7) Wadsö, L. Measuring chemical heat production rates of biofuels by isothermal calorimetry for hazardous evaluation modelling. Fire and Materials 2007, 31, 241-255.

(8) Munir, S.; Daood, S. S.; Nimmo, W.; Cunliffe, A. M.; Gibbs, B. M. Thermal analysis and devolatilization kinetics of cotton stalk, sugar cane bagasse and shea meal under nitrogen and air atmospheres. Bioresource Technology 2009, 100, 1413-1418.

(9) García-Torrent, J.; Fernandez Anez, N.; Medic Pejic, L.; Montenegro Mateos, L. Assessment of self-ignition risks of solid biofuels by thermal analysis. Fuel 2015, 143, $484-491$.

(10) Jones, J. M.; Saddawi, A.; Dooley, B.; Mitchell, E. J. S.; Werner, J.; Waldron, D. J.; Weatherstone, S.; Williams, A. Low temperature ignition of biomass. Fuel Processing Technology 2015, 134, 372-377.

(11) Topf, P. Die thermische Zersetzung von Holz bei Temperaturen bis $180 \mathrm{C}$ - Zweite Mitteilung: Versuche zur Frage der Selbstentzündung, des Gewichtsverlustes, des Brennwertes und der Elementaranalysen. Holz als Roh- und Werkstoff 1971, 29, 295-300.

(12) Cordero, T.; Rodriguez-Maroto, J. M.; Garcia, F.; Rodriguez, J. J. Thermal decomposition of wood in oxidizing atmosphere. A kinetic study from non-isothermal TG experiments. Thermochimica Acta 1991,

(13) Amutio, M.; Lopez, G.; Aguado, R.; Artetxe, M.; Bilbao, J.; Olazar, M. Kinetic study of lignocellulosic biomass oxidative pyrolysis. Fuel 2012, 95, 305-311.

(14) Anca-Couce, A.; Zobel, N.; Berger, A.; Behrendt, F. Smouldering of pine wood: Kinetics and reaction heats. Combustion and Flame 2012, 159, 1708-1719. 
(15) Broström, M.; Nordin, A.; Pommer, L.; Branca, C.; Di Blasi, C. Influence of torrefaction on the devolatilization and oxidation kinetics of wood. Journal of Analytical and Applied Pyrolysis 2012, 96, 100-109.

(16) Branca, C.; Di Blasi, C. A unified mechanism of the combustion reactions of lignocellulosic fuels. Thermochimica Acta 2013, 565, 58-64.

(17) Niu, H.; Liu, N. Thermal decomposition of pine branch: Unified kinetic model on pyrolytic reactions in pyrolysis and combustion. Fuel 2015, 160, 339-345.

(18) Branca, C.; Di Blasi, C. Global interinsic kinetics of wood oxidation. Fuel 2004, 83, $81-87$.

(19) Safi, M. J.; Mishra, I. M.; Prasad, B. Global degradation kinetics of pine needles in air. Thermochimica Acta 2004, 412, 155-162.

(20) Shen, D. K.; Gu, S.; Luo, K. H.; Bridgwater, A. V.; Fang, M. X. Kinetic study on thermal decomposition of woods in oxidative environment. Fuel 2009, 88, 1024-1030.

(21) Ohlemiller, T. J. Modeling of smoldering combustion propagation. Progress in Energy and Combustion Science 1985, 11, 277-310.

(22) Senneca, O.; Chirone, R.; Salatino, P. A Thermogravimetric Study of Nonfossil Solid Fuels. 2. Oxidative Pyrolysis and Char Combustion. Energy $\&$ Fuels 2002, 16, 661-668.

(23) Font, R.; Conesa, J. A.; Moltó, J.; Muñoz, M. Kinetics of pyrolysis and combustion of pine needles and cones. Journal of Analytical and Applied Pyrolysis 2009, 85, 276-286.

(24) Abreu Naranjo, R.; Conesa, J.; Foppa Pedretti, E.; Romero Romero, O. Kinetic analysis: Simultaneous modelling of pyrolysis and combustion processes of dichrostachys cinerea. Biomass and Bioenergy 2012, 36, 170-175. 
(25) Huang, X.; Rein, G. Thermochemical conversion of biomass in smouldering combustion across scales: The roles of heterogeneous kinetics, oxygen and transport phenomena. Bioresource Technology 2016, 20\%, 409-421.

(26) Benkorichi, S.; Fateh, T.; Richard, F.; Consalvi, J.-L.; Nadjai, A. Investigation of thermal degradation of pine needles using multi-step reaction mechanisms. Fire Safety Journal 2017, 91, 811-819.

(27) Prins, M. J.; Ptasinski, K. J.; Janssen, F. J. J. G. Torrefaction of wood: Part 1. Weight loss kinetics. Journal of Analytical and Applied Pyrolysis 2006, 77, 28-34.

(28) Chen, W.-H.; Kuo, P.-C. Torrefaction and co-torrefaction characterization of hemicellulose, cellulose and lignin as well as torrefaction of some basic constituents in biomass. Energy 2011, 36, 803-811.

(29) Ren, S.; Lei, H.; Wang, L.; Bu, Q.; Chen, S.; Wu, J. Thermal behaviour and kinetic study for woody biomass torrefaction and torrefied biomass pyrolysis by TGA. Biosystems Engineering 2013, 116, 420-426.

(30) Khazraie Shoulaifar, T.; DeMartini, N.; Karlström, O.; Hupa, M. Impact of organically bonded potassium on torrefaction: Part 1. Experimental. Fuel 2016, 165, 544-552.

(31) Alves, S. S.; Figueiredo, J. L. Pyrolysis kinetics of lignocellulosic materials by multistage isothermal thermogravimetry. Journal of Analytical and Applied Pyrolysis 1988, 13, $123-134$.

(32) Becidan, M.; Várhegyi, G.; Hustad, J. E.; Skreiberg, Ø. Thermal Decomposition of Biomass Wastes. A Kinetic Study. Industrial \& Engineering Chemistry Research 2007, $46,2428-2437$.

(33) Várhegyi, G.; Sebestyén, Z.; Czégény, Z.; Lezsovits, F.; Könczöl, S. Combustion Kinetics of Biomass Materials in the Kinetic Regime. Energy \& Fuels 2011, 26, 1323-1335. 
(34) Nik-Azar, M.; Hajaligol, M. R.; Sohrabi, M.; Dabir, B. Mineral matter effects in rapid pyrolysis of beech wood. Fuel Processing Technology 1997, 51, 7-17.

(35) Di Blasi, C. Modeling chemical and physical processes of wood and biomass pyrolysis. Progress in Energy and Combustion Science 2008, 34, 47-90.

(36) Saddawi, A.; Jones, J. M.; Williams, A. Influence of alkali metals on the kinetics of the thermal decomposition of biomass. Fuel Processing Technology 2012, 104, 189-197.

(37) Wang, S.; Dai, G.; Yang, H.; Luo, Z. Lignocellulosic biomass pyrolysis mechanism: A state-of-the-art review. Progress in Energy and Combustion Science 2017, 62, 33-86.

(38) Sárossy, Z.; Plackett, D.; Egsgaard, H. Carbohydrate analysis of hemicelluloses by gas chromatography-mass spectrometry of acetylated methyl glycosides. Analytical and Bioanalytical Chemistry 2012, 403, 1923-1930.

(39) Grønli, M.; Antal, M. J.; Várhegyi, G. A Round-Robin Study of Cellulose Pyrolysis Kinetics by Thermogravimetry. Industrial \& Engineering Chemistry Research 1999, 38, 2238-2244.

(40) Grønli, M. G.; Várhegyi, G.; Blasi, C. D. Thermogravimetric Analysis and Devolatilization Kinetics of Wood. Industrial and Engineering Chemistry Research 2002, 41, 42014208.

(41) Pyle, D. L.; Zaror, C. A. Heat transfer and kinetics in the low temperature pyrolysis of solids. Chemical Engineering Science 1984, 39, 147-158.

(42) Hayhurst, A. N. The kinetics of the pyrolysis or devolatilisation of sewage sludge and other solid fuels. Combustion and Flame 2013, 160, 138-144.

(43) Frank-Kamenetskii, D. A. Diffusion and Heat Transfer in Chemical Kinetics, 2nd ed.; Plenum Press, 1969; English translation by J. P. Appleton. 
(44) Rogers, F. E.; Ohlemiller, T. J. Cellulosic Insulation Material I. Overall Degradation Kinetics and Reaction Heats. Combustion Science and Technology 1980, 24, 129-137.

(45) Conesa, J. A.; Domene, A. Biomasses pyrolysis and combustion kinetics through n-th order parallel reactions. Thermochimica Acta 2011, 523, 176-181.

(46) Di Blasi, C. Combustion and gasification rates of lignocellulosic chars. Progress in Energy and Combustion Science 2009, 35, 121-140.

(47) Anca-Couce, A. Reaction mechanisms and multi-scale modelling of lignocellulosic biomass pyrolysis. Progress in Energy and Combustion Science 2016, 53, 41-79.

(48) Ebringerová, A.; Hromádková, Z.; Heinze, T. Polysaccharides I; Springer-Verlag, 2005; pp 1-67.

(49) Chen, H. Biotechnology of Lignocellulose; Springer Netherlands, 2014.

(50) Beall, F. C. Differential calometric analysis of wood and wood components. Wood Science and Technology 1971, 5, 159-175.

(51) Werner, K.; Pommer, L.; Broström, M. Thermal decomposition of hemicelluloses. Journal of Analytical and Applied Pyrolysis 2014, 110, 130-137.

(52) Dussan, K.; Dooley, S.; Monaghan, R. Integrating compositional features in model compounds for a kinetic mechanism of hemicellulose pyrolysis. Chemical Engineering Journal 2017, 328, 943-961.

(53) Antal, M. J.; Varhegyi, G. Cellulose Pyrolysis Kinetics: The Current State of Knowledge. Industrial 83 Engineering Chemistry Research 1995, 34, 703-717.

(54) Jensen, A.; Dam-Johansen, K.; Wójtowicz, M. A.; Serio, M. A. TG-FTIR Study of the Influence of Potassium Chloride on Wheat Straw Pyrolysis. Energy \& Fuels 1998, 12, 929-938. 
(55) Eom, I.-Y.; Kim, J.-Y.; Kim, T.-S.; Lee, S.-M.; Choi, D.; Choi, I.-G.; Choi, J.-W. Effect of essential inorganic metals on primary thermal degradation of lignocellulosic biomass. Bioresource Technology 2012, 104, 687-694.

(56) Khazraie Shoulaifar, T.; DeMartini, N.; Karlström, O.; Hemming, J.; Hupa, M. Impact of organically bonded alkali metals on torrefaction: Part 2. Modeling. Fuel 2016, 168, $107-115$.

(57) Orfão, J. J. M.; Antunes, F. J. A.; Figueiredo, J. L. Pyrolysis kinetics of lignocellulosic materials - three independent reactions model. Fuel 1999, 78, 349-358. 